\title{
Inclusion of vegetation in the Town Energy Balance model for modelling urban green areas
}

\author{
A. Lemonsu ${ }^{1}$, V. Masson ${ }^{1}$, L. Shashua-Bar ${ }^{2}$, E. Erell ${ }^{2}$, and D. Pearlmutter ${ }^{2}$ \\ ${ }^{1}$ Météo France/CNRS, URA1357, Centre de Recherches Météorologiques, Toulouse, France \\ ${ }^{2}$ Jacob Blaustein Institutes for Desert Research, Ben-Gurion University of the Negev, Israel
}

Correspondence to: A. Lemonsu (aude.lemonsu@ meteo.fr)

Received: 24 April 2012 - Published in Geosci. Model Dev. Discuss.: 25 May 2012

Revised: 14 September 2012 - Accepted: 1 October 2012 - Published: 9 November 2012

\begin{abstract}
Cities impact both local climate, through urban heat islands and global climate, because they are an area of heavy greenhouse gas release into the atmosphere due to heating, air conditioning and traffic. Including more vegetation into cities is a planning strategy having possible positive impacts for both concerns. Improving vegetation representation into urban models will allow us to address more accurately these questions. This paper presents an improvement of the Town Energy Balance (TEB) urban canopy model. Vegetation is directly included inside the canyon, allowing shadowing of grass by buildings, better representation of urban canopy form and, a priori, a more accurate simulation of canyon air microclimate. The surface exchanges over vegetation are modelled with the well-known Interaction Soil Biosphere Atmosphere (ISBA) model that is integrated in the TEB's code architecture in order to account for interactions between natural and built-up covers. The design of the code makes possible to plug and use any vegetation scheme. Both versions of TEB are confronted to experimental data issued from a field campaign conducted in Israel in 2007. Two semi-enclosed courtyards arranged with bare soil or watered lawn were instrumented to evaluate the impact of landscaping strategies on microclimatic variables and evapotranspiration. For this case study, the new version of the model with integrated vegetation performs better than if vegetation is treated outside the canyon. Surface temperatures are closer to the observations, especially at night when radiative trapping is important. The integrated vegetation version simulates a more humid air inside the canyon. The microclimatic quantities (i.e., the street-level meteorological variables) are better
\end{abstract}

simulated with this new version. This opens opportunities to study with better accuracy the urban microclimate, down to the micro (or canyon) scale.

\section{Introduction}

Numerous models have been developed in the last ten years in order to parameterise the surface exchanges between urban covers and atmosphere. These models are dedicated to different types of applications - from climate studies to numerical weather prediction or air quality - and, thus, incorporate different levels of complexity. In recent years, many studies focus on modelling the impact of urban planning on the microclimate felt by the inhabitants. One goal is especially to be able to evaluate different strategies of urban development for a given city in response to climate change. Such issues require appropriate modelling tools in order to represent fine-scale physical processes, while retaining the numerical ability to model the urban climate at the scale of the entire city.

One strategy that is often considered in order to improve human comfort by reducing the effects of urban heat island is the greening of cities. However, all existing models of urban climate are not able to represent urban vegetation and its impact on microclimate with the same relevance. Indeed, one of the noticeable differences between these models is the possibility (or not) of taking into account vegetation for the urban environments that include green areas, and how this vegetation is processed by the models. Of the 31 models 
which were involved in the international urban energy balance model comparison (Grimmond et al., 2010, 2011), eight models deal exclusively with artificial surfaces without considering vegetation (e.g., Martilli et al., 2002; Kanda et al., 2005; Kondo et al., 2005; Krayenhoff and Voogt, 2007; Salamanca et al., 2010). The vast majority of other models decompose the surface according to distinct types of covers, more particularly by distinguishing impervious surfaces and natural covers (soils and vegetation) (Essery et al., 2003; Dupont and Mestayer, 2006; Porson et al., 2009). Each cover type is associated with a specific parameterisation that computes water, energy and momentum fluxes between surface and atmosphere. The fluxes are then aggregated at the gridmesh scale according to the respective cover fractions. This approach by tiles is adapted to mesoscale atmospheric modelling when the surface characteristics are relatively spatially homogeneous. The aggregated surface fluxes that are used by the atmospheric model for lower boundary conditions are realistic enough.

Today, very few models incorporate explicitly the vegetation in the urban landscape in order to model the very local interactions. Shashua-Bar and Hoffman $(2002,2004)$ in their Green CTTC model, include thermal effects of shade trees in the Cluster Thermal Time Constant (CTTC) analytical model, derived from solar radiation exchange. We can also mention the recent development of the Vegetated Urban Canopy Model (VUCM) of Lee and Park (2008) which takes into account the presence and effects of vegetation in the radiative, energetic and dynamic calculations. Good performances were obtained by evaluating the model for Vancouver and Marseille field experiments. But the benefit of the integrated approach over the tiling approach was not studied and quantified.

Based on the tiling approach, SURFEX (SURFace EXTernalisée in French) is the externalised land-surface modelling system (Salgado and Moigne, 2010; Masson et al., 2012) that has been developed at Meteo-France. It can be run in a coupled way with different meteorological models, e.g., the Meso-NH research model (Lafore et al., 1998) or the AROME weather forecasting model (Seity et al., 2011), as well as in offline configuration using atmospheric forcing coming from analyses or observation at a given height above the top of the canopy. SURFEX notably includes the Interaction between Soil Biosphere and Atmosphere (ISBA) model (Noilhan and Planton, 1989) for soil and vegetation, and the Town Energy Balance (TEB) model (Masson, 2000) for urban covers.

For urban landscapes with green areas, SURFEX is run with TEB and ISBA models but without direct micro-scale interactions (Fig. 1a). In view of the horizontal scale of study - few tens of metres in residential areas combining houses and private gardens - this design presents some obvious limitations:
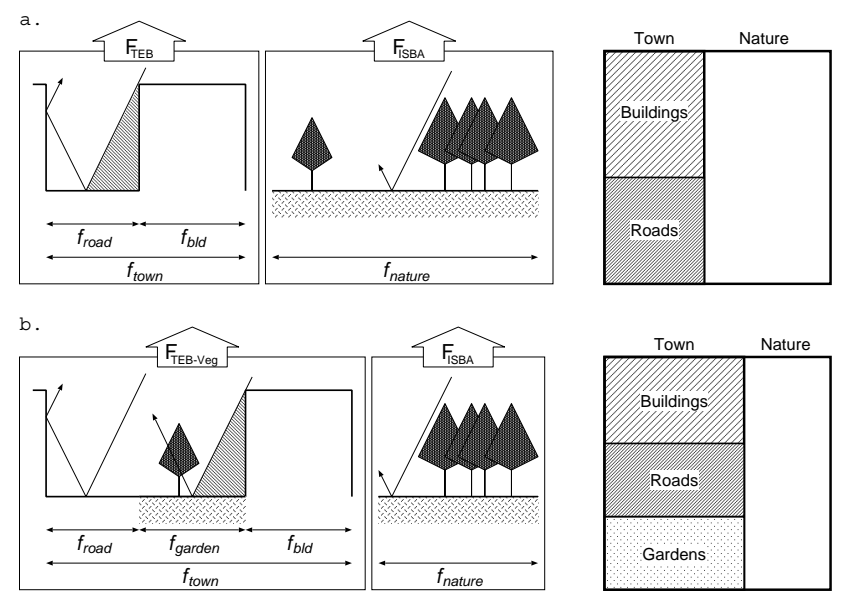

Fig. 1. Comparison of tiling approaches applied in TEB-ISBA (top) and TEB-Veg (bottom) to compute surface fluxes for a SURFEX's grid point containing pervious and impervious covers.

1. the vegetation is considered as an open area that is not subject to shadow effects of buildings and to radiation trapping within the canyon;

2. unrealistic geometric parameters are prescribed for TEB. Due to some conservative constraints for the resolution of the radiation budget, the canyons are assumed to bo more narrow than reality (the vegetation is placed outside the canyon as described in Fig. 1a contrary to Fig. 1b);

3. the turbulent fluxes, especially for vegetation, are calculated using inadequate conditions since they are based on meteorological forcing (wind, air temperature and humidity) provided above buildings instead of within the street;

4. the 2-m air temperature and humidity are simply calculated as an arithmetic average of the 2-m air temperature and humidity provided independently by the two models.

Most of the urban sites on which TEB was run with ISBA (Masson et al., 2002; Lemonsu et al., 2004; Offerle et al., 2005; Roberts et al., 2006; Hamdi and Masson, 2008; Pigeon et al., 2008) are predominantly composed of impervious covers - at least $84 \%$ - so that the surface exchanges are little impacted by vegetation. However, when urban landscapes are more heterogeneous at grid-mesh scale, especially in residential areas where the proportion of vegetation is significant, the subgrid variability of the fluxes can be high. These various limitations of the tiling approach is confirmed by Grimmond et al. $(2010,2011)$ within the framework of the intercomparison exercise of urban models. They clearly display the better performances of the models that integrate urban vegetation in the modelling of upward radiation and 
energy fluxes. Besides, we can expect even greater impact on microclimatic variables such as air temperature at streetgarden level, which has not been studied in the intercomparison.

The objective of the present study is to improve the representation of urban green areas in the SURFEX modelling system by including the parameterisation of air/vegetation exchanges directly in the TEB model. This work is an important scientific issue for the improvement of the urban micro-climate modelling and the weather prediction for cities (more particularly for residential areas), but also for the environmental modelling and more particularly for the evaluation of urban-planning programmes focusing on mitigation/adaptation strategies and thermal comfort of inhabitants. We developed a new version of TEB that includes the ground-based vegetation inside the canyons (Fig. 1b) such as private gardens and backyards, as well as trees inside the streets, but also the green roofs and walls. In the first stage, presented here, we focus on the representation of the gardens, more particularly the low vegetation. The general methodology applied in the new TEB-Veg version of the urban model is described in Sect. 2. It is followed by the presentation of the developments made to the inclusion of vegetation in radiation budget (Sect. 3) and turbulent exchanges (Sect. 4). Finally, an evaluation exercise is proposed in Sect. 5 in order to compare the simulations performed by TEB and ISBA (without interaction) and by TEB-Veg before concluding in Sect. 6.

\section{Description of urban vegetation in TEB-Veg}

According to the types of land uses and covers and the level of subgrid heterogeneity, it is not always relevant to take into account the interactions between impervious covers and vegetation. The distinction is done between pure vegetation that is not influenced by the presence of impervious covers within the same grid-mesh (e.g., forest, crops, large parks), and urban vegetation that is part of the urban landscape. The first one is modelled following the tiling approach of SURFEX by the ISBA model that runs over the vegetation tile (Fig. 1a), whereas the second one is included in the urban tile and modelled by TEB as a component of the urban canyon as described in Fig. 1b. This new version of TEB is called TEBVeg and is described in details in the next sections.

In terms of functional processes, modelling of urban vegetation does not require specific parameterisation implementing new mechanisms. Only descriptive parameters associated with soil and vegetation should be adjusted, such as leaf area index or tree height. Therefore, we have chosen to use the ISBA model that is already available in the SURFEX platform for the computation of heat, humidity and momentum fluxes of gardens. But in the case of urban vegetation, ISBA is called from TEB and is subject to forcing conditions coming from the canyon. Thus, over a single grid mesh that would be composed of a vegetation tile and an urban tile with a fraction of urban vegetation, ISBA would be run twice independently, i.e., once for the vegetation tile and once for the urban vegetation from the urban tile (Fig. 1b, right).

This modelling approach leads to a new architecture of the code described in Fig. 2. The SURFEX tile dedicated to urban covers is now associated to the TEB-Veg model that includes successive calculation steps:

- The short- and long-wave radiation calculations inside the canyon (with or without vegetation) that take into account the shadow effects and the multiple reflections are externalised from the initial code of TEB for impervious surfaces in order to be done before the TEB and ISBA calculations.

- The "urban vegetation" version of ISBA model is run in order to compute water, energy and momentum surface exchanges over gardens. The influences and contributions of canyon geometry and impervious covers are taken into account by forcing ISBA with the street-level atmospheric conditions (temperature, humidity and wind inside canyon calculated at the previous timestep) and new short- and long-wave radiation received by gardens.

- The TEB model is run in order to compute water, energy and momentum surface exchanges over the impervious covers (roofs, roads, walls). The contributions of gardens take place through the long-wave emission that is received by roads and walls.

- The TEB-Veg model aggregates the surface fluxes proportionally to the partitions between roofs, walls, roads and gardens. It also computes the air temperature and humidity within the canyon starting from the heat and humidity fluxes associated with walls, roads and gardens (and additional anthropogenic heat and humidity sources due to traffic).

The modelling strategy chosen here requires to only change the input arguments sent to the ISBA model without modifying the model itself (the ISBA physics remains unchanged). All ISBA variables have to be duplicated in order to distinguish pure vegetation and urban vegetation, and the initialisation of ISBA's input parameters and prognostic variables must be done separately for these two types of vegetation. This design has several advantages: (1) the model can be run with any versions of ISBA, such as Force-restore (Noilhan and Planton, 1989), diffusion (Boone et al., 2000), A-gs (Calvet et al., 1998) and with the different physical options, e.g., vegetation growth (Calvet et al., 1998) or $\mathrm{CO}_{2}$ fluxes (Gibelin et al., 2008); (2) the future updates of ISBA could be easily integrated in the model; and (3) ISBA could be replaced by another surface-vegetation-atmosphere transfer model. 


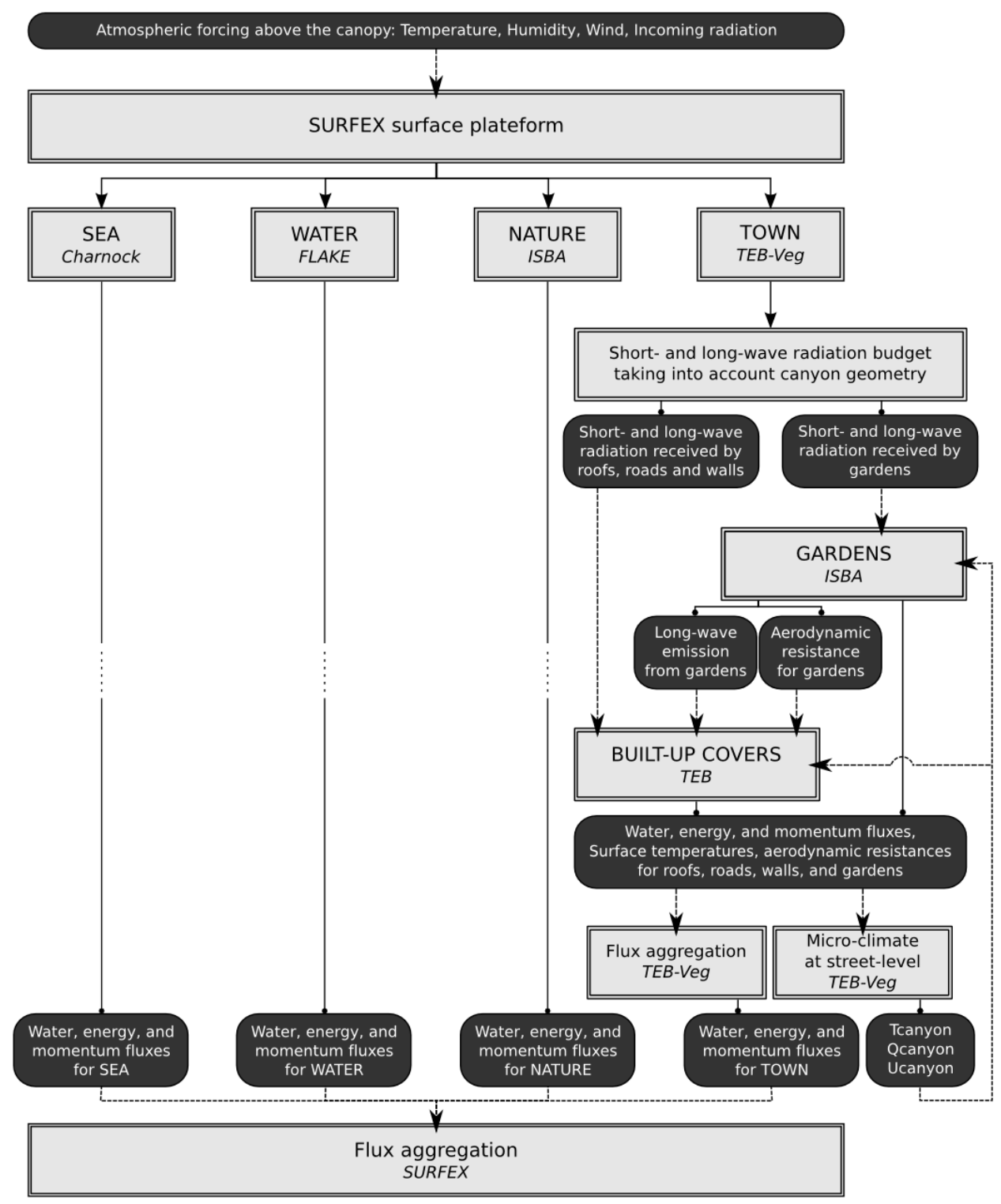

Fig. 2. Diagram describing the inclusion of urban vegetation in the TEB's code within the tiling approach of SURFEX.

\section{Radiation budget}

\subsection{Solar radiation}

The model computes the solar radiation budget - for direct and diffuse solar radiation components - inside the canyon by taking into account the shadow effects due to buildings and the multiple reflections on urban facets. A new development (see Appendix A) now allows to specify a canyon orientation. In this case, one wall is completely in shadows, while the other is totally or partially under sunlight. Even in the case it is partially sunlit, only one energy budget will be solved for each wall. This means that the solar radiation received by the sunlit and shadowed parts of the wall will be averaged into a mean solar forcing for this wall. Because both walls now receive a distinct solar forcing, solar reflection is affected (see Appendix A), as well as surface temperature evolutions, long-wave emission and the other terms of the energy balance. The two opposite walls will then follow a distinct diurnal cycle. Shadows on roads and gardens are also influenced by the choice of the canyon orientation, modifying the solar radiation received by the street. However, as for walls, only one energy balance will be solved.

The inclusion of gardens in the canyon is resolved with a simple approach. First, gardens are composed of low vegetation that does not obstruct the penetration of radiation inside canyons. Second, roads and gardens are arranged in an 
equiprobable way. As a result, they are only associated with a cover fraction, and have the same sky-view factor.

The amount of energy $\mathcal{A}_{\mathrm{r}}(\infty), \quad \mathcal{A}_{\mathrm{g}}(\infty), \quad \mathcal{A}_{\mathrm{w}_{\mathrm{A}}}(\infty)$, $\mathcal{A}_{\mathrm{w}_{\mathrm{B}}}(\infty)$ reached at the four surfaces (roads, garden, walls $\mathrm{A}$ and $\mathrm{B}$ ) is computed in a way shown in Appendix A.

\subsection{Longwave radiation}

The longwave radiation is another important part of the energy budget. As explained above, there is only one energy balance for each one of the four surfaces (road, gardens, the two walls), leading then to only one surface temperature for each. As a consequence, TEB does not separate the surface temperatures of sunlit and shaded parts of each surface, but computes an averaged temperature (and then longwave radiation) for each.

By accounting for gardens inside canyons, new contributions appear in the calculation of the longwave radiation absorbed by each facet, considering snow-free and snow-covered fractions for roads and gardens. According to Masson (2000), it is assumed that beyond two reflections, the energy absorbed by the facet becomes negligible. Thus, the long-wave radiation absorbed by roads, gardens and walls, respectively, is expressed as:

$$
\begin{aligned}
L_{\mathrm{r}}^{*}= & -\tilde{\epsilon}_{\mathrm{r}} \sigma \tilde{T}_{\mathrm{r}}^{4} \\
& +\left\{\tilde{\epsilon}_{\mathrm{r}} \Psi_{\mathrm{r}}+\tilde{\epsilon}_{\mathrm{r}}\left(1-\epsilon_{\mathrm{w}}\right) \Psi_{\mathrm{w}}\left(1-\Psi_{\mathrm{r}}\right)\right\} L^{\downarrow} \\
& +\left\{\tilde{\epsilon}_{\mathrm{r}} \epsilon_{\mathrm{w}}\left(1-\Psi_{\mathrm{r}}\right)+\tilde{\epsilon}_{\mathrm{r}} \epsilon_{\mathrm{w}}\left(1-\epsilon_{\mathrm{w}}\right)\left(1-\Psi_{\mathrm{r}}\right)\left(1-2 \Psi_{\mathrm{w}}\right)\right\} \sigma \tilde{T}_{\mathrm{w}}^{4} \\
& +\delta_{\mathrm{r}} \tilde{\epsilon}_{\mathrm{r}}^{2}\left(1-\epsilon_{\mathrm{w}}\right)\left(1-\Psi_{\mathrm{r}}\right) \Psi_{\mathrm{w}} \sigma \tilde{T}_{\mathrm{r}}^{4} \\
& +\delta_{g} \tilde{\epsilon}_{\mathrm{r}} \tilde{\epsilon}_{g}\left(1-\epsilon_{\mathrm{w}}\right)\left(1-\Psi_{\mathrm{r}}\right) \Psi_{\mathrm{w}} \sigma \tilde{T}_{\mathrm{g}}^{4}
\end{aligned}
$$

$$
\begin{aligned}
L_{\mathrm{g}}^{*}= & -\tilde{\epsilon}_{\mathrm{g}} \sigma \tilde{T}_{\mathrm{g}}^{4} \\
& +\left\{\tilde{\epsilon}_{\mathrm{g}} \Psi_{\mathrm{r}}+\tilde{\epsilon}_{\mathrm{g}}\left(1-\epsilon_{\mathrm{w}}\right) \Psi_{\mathrm{w}}\left(1-\Psi_{\mathrm{r}}\right)\right\} L^{\downarrow} \\
& +\left\{\tilde{\epsilon}_{\mathrm{g}} \epsilon_{\mathrm{w}}\left(1-\Psi_{\mathrm{r}}\right)+\tilde{\epsilon}_{\mathrm{g}} \epsilon_{\mathrm{w}}\left(1-\epsilon_{\mathrm{w}}\right)\left(1-\Psi_{\mathrm{r}}\right)\left(1-2 \Psi_{\mathrm{w}}\right)\right\} \sigma \tilde{T}_{\mathrm{w}}^{4} \\
& +\delta_{\mathrm{r}} \tilde{\epsilon}_{\mathrm{r}} \tilde{\epsilon}_{\mathrm{g}}\left(1-\epsilon_{\mathrm{w}}\right)\left(1-\Psi_{\mathrm{r}}\right) \Psi_{\mathrm{w}} \sigma \tilde{T}_{\mathrm{r}}^{4} \\
& +\delta_{\mathrm{g}} \tilde{\epsilon}_{\mathrm{g}}^{2}\left(1-\epsilon_{\mathrm{w}}\right)\left(1-\Psi_{\mathrm{r}}\right) \Psi_{\mathrm{w}} \sigma \tilde{T}_{\mathrm{g}}^{4}
\end{aligned}
$$$$
L_{\mathrm{w}_{\mathrm{A}}}^{*}=-\epsilon_{\mathrm{w}} \sigma T_{\mathrm{w}_{\mathrm{A}}}^{4}
$$$$
+\left\{\epsilon_{\mathrm{w}} \Psi_{\mathrm{w}}+\delta_{\mathrm{r}} \epsilon_{\mathrm{w}}\left(1-\tilde{\epsilon}_{\mathrm{r}}\right) \Psi_{\mathrm{w}} \Psi_{\mathrm{r}}\right.
$$$$
+\delta_{\mathrm{g}} \epsilon_{\mathrm{w}}\left(1-\tilde{\epsilon}_{\mathrm{g}}\right) \Psi_{\mathrm{w}} \Psi_{\mathrm{r}}
$$$$
\left.+\epsilon_{\mathrm{w}}\left(1-\epsilon_{\mathrm{W}}\right) \Psi_{\mathrm{w}}\left(1-2 \Psi_{\mathrm{w}}\right)\right\} L^{\downarrow}
$$$$
+\left\{\delta_{\mathrm{r}} \epsilon_{\mathrm{w}}^{2}\left(1-\tilde{\epsilon}_{\mathrm{r}}\right) \Psi_{\mathrm{w}}\left(1-\Psi_{\mathrm{r}}\right)\right.
$$$$
\left.+\delta_{\mathrm{g}} \epsilon_{\mathrm{w}}^{2}\left(1-\tilde{\epsilon}_{\mathrm{g}}\right) \Psi_{\mathrm{w}}\left(1-\Psi_{\mathrm{r}}\right)\right\} \sigma \tilde{T}_{\mathrm{w}}^{4}
$$$$
+\left\{\epsilon_{\mathrm{w}}^{2}\left(1-\epsilon_{\mathrm{w}}\right)\left(1-2 \Psi_{\mathrm{w}}\right)^{2}\right\} \sigma T_{\mathrm{w}_{\mathrm{A}}}^{4}
$$$$
+\left\{\epsilon_{\mathrm{w}}^{2}\left(1-2 \Psi_{\mathrm{w}}\right) \epsilon_{\mathrm{w}}\right\} \sigma T_{\mathrm{w}_{\mathrm{B}}}^{4}
$$$$
+\delta_{\mathrm{r}}\left\{\epsilon_{\mathrm{w}} \tilde{\epsilon}_{\mathrm{r}} \Psi_{\mathrm{w}}+\tilde{\epsilon}_{\mathrm{r}} \epsilon_{\mathrm{w}}\left(1-\epsilon_{\mathrm{w}}\right) \Psi_{\mathrm{w}}\left(1-2 \Psi_{\mathrm{w}}\right)\right\} \sigma \tilde{T}_{\mathrm{r}}^{4}
$$$$
+\delta_{\mathrm{g}}\left\{\epsilon_{\mathrm{w}} \tilde{\epsilon}_{\mathrm{g}} \Psi_{\mathrm{w}}+\tilde{\epsilon}_{\mathrm{g}} \epsilon_{\mathrm{w}}\left(1-\epsilon_{\mathrm{w}}\right) \Psi_{\mathrm{w}}\left(1-2 \Psi_{\mathrm{w}}\right)\right\} \sigma \tilde{T}_{\mathrm{g}}^{4}
$$

)

\section{Turbulent exchanges within the canyon}

\subsection{Urban microclimate at mid-height of building}

The original version of TEB (Masson, 2000) calculates the air temperature $T_{\text {can }}$ at mid-height of buildings starting from the balance of the heat exchanges for the air volume within the canyon. They include the interactions with the road, the walls and the atmosphere above the canyon, as well as the heat release from traffic. The same method is applied for the specific humidity $q_{\mathrm{can}}$. The contributions of the garden on the microclimate are now taken into account by including in these equations (see Appendix B) the sensible and latent heat fluxes over the vegetated surface.

\subsection{Vertical profile of meteorological fields within the canyon}

The TEB-SBL (for Surface Boundary Layer) version of TEB has been recently developed in order to improve prediction of the meteorological fields inside the street canyon (Hamdi and Masson, 2008; Masson and Seity, 2009). It resolves the 
surface boundary layer inside and above urban canopy by introducing a drag force approach - based on Yamada (1982) for vegetation canopies - in order to take into account the influence of buildings on the local atmospheric characteristics.

The equations for momentum, turbulent kinetic energy, air temperature and specific humidity follow the same general expression (here for momentum):

$$
\frac{\partial U}{\partial t}=F_{U}+\left.\frac{\partial U}{\partial t}\right|_{\mathrm{TEB}}
$$

According to Martilli et al. (2002), the momentum equation includes, besides the general forcing term $F_{U}$, a contribution from the area-average effect of the subgrid urban elements that is partitioned into a contribution from vertical surfaces (buildings and walls) and a contribution from horizontal surfaces (roofs and roads). For the present version of TEB-Veg that only takes into account low vegetation, the garden contribution is included in the horizontal term:

$$
\left.\frac{\partial U}{\partial t}\right|_{\mathrm{TEB}} ^{H}=-U_{*}^{2} \frac{S_{\mathrm{H}}}{V_{\mathrm{air}}}
$$

where $U_{*}$ is the friction velocity, $S_{\mathrm{H}}$ the horizontal surface area of roofs, roads and gardens, and $V_{\text {air }}$ the volume of air in the urban grid cell.

For temperature $(T)$ and humidity $(q)$, the contributions from gardens are taken into account through the sensible and latent heat fluxes:

$$
\begin{aligned}
& \left.\frac{\partial T}{\partial t}\right|_{\mathrm{TEB}}=\left(\frac{Q_{\mathrm{H}_{\mathrm{R}}}+Q_{\mathrm{H}_{\mathrm{r}}}+Q_{\mathrm{H}_{\mathrm{g}}}}{\rho C_{p}}\right) \frac{S_{\mathrm{H}}}{V_{\mathrm{air}}}+\frac{Q_{\mathrm{H}_{\mathrm{w}}}}{\rho C_{p}} \frac{S_{\mathrm{V}}}{V_{\mathrm{air}}} \\
& \left.\frac{\partial q}{\partial t}\right|_{\mathrm{TEB}}=\left(\frac{Q_{E_{\mathrm{R}}}+Q_{E_{\mathrm{r}}}+Q_{E_{\mathrm{g}}}}{\rho}\right) \frac{S_{\mathrm{H}}}{V_{\mathrm{air}}}
\end{aligned}
$$

with $Q_{\mathrm{H}_{\mathrm{R}}}, Q_{\mathrm{H}_{\mathrm{r}}}$, and $Q_{\mathrm{H}_{\mathrm{g}}}$ the sensible heat fluxes for roofs, roads, and gardens (same for the latent heat flux), $Q_{\mathrm{H}_{\mathrm{W}}}$ the sensible heat fluxes for walls, and $S_{\mathrm{V}}$ the vertical surface area of walls.

\subsection{Parameterisation of mixing length}

Vertical turbulent exchanges within the canyon (and also above the canyon) are parameterised with the turbulent scheme of Cuxart et al. (2000). This scheme uses an equation for the turbulent kinetic energy, and is closed with a mixing length. Hamdi and Masson (2008) use a constant mixing length within the canyon, equal to the building height. Here, we improve this representation following the works of Santiago and Martilli (2010), that used fluid dynamics models to explicitly simulate the motions within the canyon to derive a vertical profile of the mixing length.

The mixing length $(L)$ is parameterised as:

$$
\begin{array}{lll}
\frac{L}{C}=\min [2.24(h-d), z] & \text { for } & \frac{z}{h}<1 . \\
\frac{L}{C}=\max [2.24(h-d), z-d] & \text { for } & \frac{z}{h}>1.5
\end{array}
$$

with a continuous linear transition between the top of the canopy layer and the base of the inertial sublayer, and where the displacement height $d$ is also parameterised following Santiago and Martilli (2010):

$d=\max \left[\frac{3}{4} h, \lambda_{\mathrm{f}}^{0.13} h\right]$

Here $z$ is the height above ground, $h$ is the building height, $\lambda_{\mathrm{f}}$ is the frontal area density, that is derived from other TEB geometric parameters assuming no preferred direction of buildings with respect to the wind direction $\left(\lambda_{\mathrm{f}}=\left[\frac{h}{w} f_{\mathrm{bld}}\right] / \frac{\pi}{2}\right.$, with $w$ being the road width and $f_{\text {bld }}$ the building fraction). $C$ is dependant on the turbulence scheme constants and of the atmospheric stability, using Monin-Obukhov stability functions (Redelsperger et al., 2002). Note that near the surface, one limits the mixing length to reproduce the effect of the surface on the turbulent eddies.

\section{Evaluation of the model}

An evaluation exercise is performed against experimental data in order to compare the performances of the initial version of the system running separately for vegetation with ISBA and impervious covers with TEB (referred to as TEBISBA) and the new version of the system which directly includes vegetation within canyons (referred to as TEB-Veg) for the urban micro-climate modelling. Note that for this study, the vertical profiles within the canyon are computed following TEB-SBL described in Sect. 4.2.

\subsection{Experimental data}

This work is based on the experimental campaign carried out by Shashua-Bar et al. (2009) at the Sde-Boqer campus in the arid Negev Highlands region of southern Israel $\left(30.85^{\circ} \mathrm{N}\right.$, $34.78^{\circ} \mathrm{E}, 475 \mathrm{~m}$ altitude, Fig. 3) during summer 2007. Two adjacent courtyard spaces - identical in terms of geometry and material characteristics - were laid out according to six various landscaping strategies. These latter consist in different combinations of bare soil, grass or trees, and the use of fabric meshes extended at the top of the courtyard to make shadow. All characteristics are detailed by Shashua-Bar et al. (2009) and two examples of the landscaping strategies are presented in their Fig. 2. In the present study, we focus on two landscaping strategies only: Exposed-Bare $(70 \%$ of pavement and $30 \%$ of bare soil within the courtyard), and Exposed-Grass (20\% of pavement and $80 \%$ of lawn).

The courtyards were instrumented to document the local microclimate (i.e., the meteorological variables inside the urban canopy) and to characterise the variability of outdoor comfort according to urban arrangement and landscaping. During the period July-August 2007, 3-4 consecutive days at most were devoted to each landscaping strategy. The microclimatic data collected during the experiment where air temperature, relative humidity, vapour pressure and wind speed 


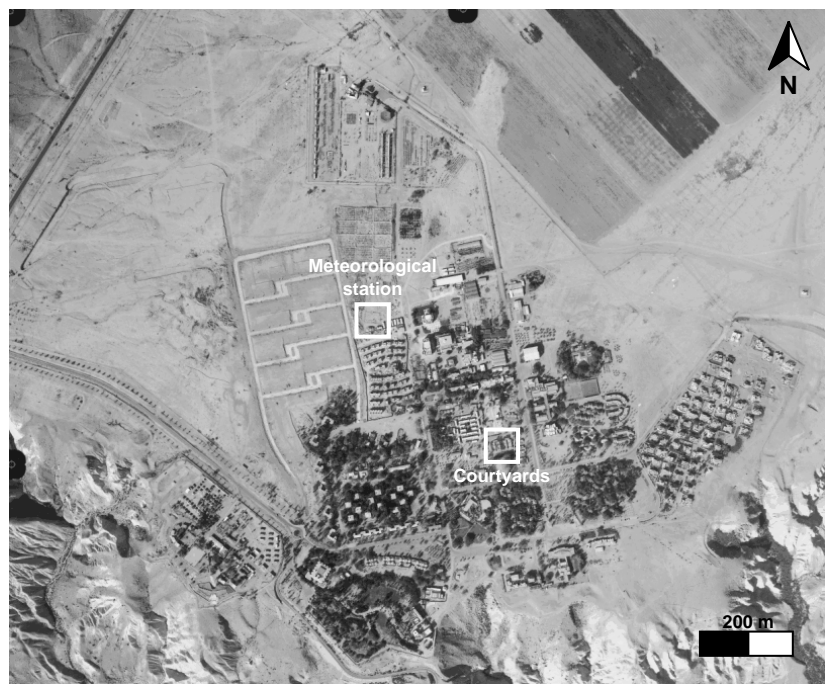

Fig. 3. Aerial photograph of the Sde-Boqer experimental site. The location of the instrumented courtyards and the meteorological station is pointed out by the two white frames.

at $1.5 \mathrm{~m}$ above ground level (a.g.l.) in the centre of the courtyards (see Fig. 1 of Shashua-Bar et al., 2009). They were completed by radiation measurements on the roof (incoming, outgoing and net radiation), and by surface temperature measurements of various covers (eastern, western, and southfacing walls, pavement, and grass according to the strategy). Evapotranspiration from the lawn was also measured using custom-made mini-lysimeters as described by Shashua-Bar et al. (2009).

Finally, along with the in situ measurements, reference climatic data were obtained from the nearby meteorological station located $400 \mathrm{~m}$ northwest of the courtyard site in an open desert area (Fig. 3). It provides air temperature and humidity at $1.5 \mathrm{~m}$ a.g.1., wind speed and direction at $10 \mathrm{~m}$ a.g.l., and soil temperature.

\subsection{Configuration of the numerical experiment}

For the comparison with observations, SURFEX is run in offline mode on a single grid point. Given the simple morphology of the experimental site, the assumptions applied in TEB (single urban canyon, mean building height and flat roofs) are relevant to this case study. Besides, although TEB has historically been developed for mesoscale modelling, its recent improvements allow a description of the physical processes inside the canyon detailed enough to be compared with the microscale measurements that are presented here. Above all, TEB is closer to the real configuration of the experimental site by taking into account the specific orientation of the street for radiative calculations.

Most of TEB's and ISBA's input parameters can be directly prescribed thanks to a very accurate description of the experimental site (Shashua-Bar et al., 2009). Buildings that
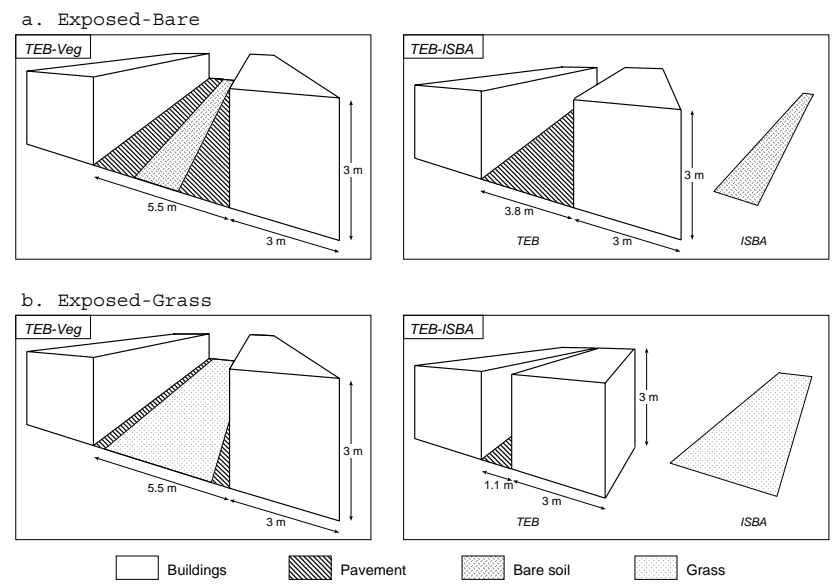

Fig. 4. Schematic of the simplified urban canyon as described in TEB-Veg (left) and TEB-ISBA (right) to represent the experimental site for the Exposed-Bare and Exposed-Grass experiments.

surround the courtyards are contiguous blocks of $3 \mathrm{~m}$ high with flat roofs. They are made of lightweight concrete both for walls and roofs. The pavement is a thin layer of concrete paving blocks $4 \mathrm{~cm}$ thick over natural soil. All impervious surfaces have light colours, so that albedos are rather high. Thermal and radiative properties of roofs, walls and roads that remain unchanged whatever the landscaping strategy are listed in Table 1.

In order to fit with the concept of infinite canyon applied in TEB (without intersections), and to compute its geometric parameters without overestimating the building fraction and the wall density, a reference pattern composed of 1 building and 1 courtyard is chosen to represent the experimental site (Fig. 4a left). In addition, to best match the real configuration of the site, the orientation of the canyon is fixed to $12^{\circ} \mathrm{E}$ in TEB, in contrast to the usual assumption that assumes isotropic directions for the streets at the scale of a grid point of the model. All TEB's input parameters are then calculated for the two versions of the code and for the different landscaping strategies studied here.

Only the landscaping within the courtyards are modified from one strategy to another, not the urban canyon geometry. For TEB-ISBA, however, the modification of partitioning between pervious and impervious covers is reflected by a change in the geometric parameters prescribed for the model. As shown in Fig. 4, the idealised canyon has an aspect ratio of 0.54 , which is the case for TEB-Veg since the vegetation is explicitly included between buildings. But for TEBISBA which separates vegetation and impervious covers, the canyon is artificially narrower with aspect ratios varying from 0.78 to 2.70 according to the experiment (Table 2). This will change the exposure of canyon surfaces to radiation. In addition, the wall-plan area ratio is calculated as the ratio between the wall surfaces and the ground-based surface that includes only impervious covers in TEB-ISBA, and impervious 
Table 1. TEB's input parameters relative to radiative and thermal characteristics of impervious covers (Source: Shashua-Bar et al., 2009, 2011).

\begin{tabular}{|c|c|c|c|c|}
\hline & & External layer & Middle layer & Internal layer \\
\hline Roof properties & & light concrete & light concrete & light concrete \\
\hline Albedo & $(-)$ & 0.40 & - & - \\
\hline Emissivity & $(-)$ & 0.90 & - & - \\
\hline Thermal conductivity & $\left(\mathrm{W} \mathrm{m}{ }^{-1} \mathrm{~K}^{-1}\right)$ & 0.70 & 0.70 & 0.70 \\
\hline Heat capacity & $\left(\mathrm{kJ} \mathrm{K}^{-1} \mathrm{~m}^{-3}\right)$ & 616.0 & 616.0 & 616.0 \\
\hline Depth & (m) & 0.04 & 0.04 & 0.04 \\
\hline Wall properties & & light concrete & light concrete & light concrete \\
\hline Albedo & $(-)$ & 0.35 & - & - \\
\hline Emissivity & $(-)$ & 0.90 & - & - \\
\hline Thermal conductivity & $\left(\mathrm{W} \mathrm{m}{ }^{-1} \mathrm{~K}^{-1}\right)$ & 0.70 & 0.70 & 0.70 \\
\hline Heat capacity & $\left(\mathrm{kJ} \mathrm{K}^{-1} \mathrm{~m}^{-3}\right)$ & 616.0 & 616.0 & 616.0 \\
\hline Depth & (m) & 0.01 & 0.04 & 0.07 \\
\hline Road properties & & dense concrete & soil & soil \\
\hline Albedo & $(-)$ & 0.40 & - & - \\
\hline Emissivity & $(-)$ & 0.90 & - & - \\
\hline Thermal conductivity & $\left(\mathrm{W} \mathrm{m}{ }^{-1} \mathrm{~K}^{-1}\right)$ & 0.70 & 0.70 & 0.70 \\
\hline Heat capacity & $\left(\mathrm{kJ} \mathrm{K}^{-1} \mathrm{~m}^{-3}\right)$ & 1776.0 & 1280.0 & 1280.0 \\
\hline Depth & $(\mathrm{m})$ & 0.05 & 0.1 & 1.0 \\
\hline
\end{tabular}

covers and gardens in TEB-Veg; it is consequently higher for TEB-ISBA than for TEB-Veg. These differences are listed in Table 2.

The properties of natural soil and vegetation are also listed in Table 2. They are the same for TEB-Veg and TEB-ISBA, but vary according to landscaping strategies. In this region, the soil is loess. The fractions of sand and clay (39 and $27 \%$, respectively) are prescribed from the FAO Harmonized World Soil Database (FAO/IIASA/ISRIC/ISSCAS/JRC, 2009). For Exposed-Grass landscaping strategy, the lawn is Durban grass which is irrigated to prevent drought stress; as a result, leaf area indexes are relatively high.

\subsection{Meteorological forcings}

For each measurement period documenting a specific landscaping strategy, a representative day was selected according to two criteria: (1) complete data available for all sensors, and (2) stable weather with clear sunny conditions, which is typical to the summer period at Sde Boqer. Weather in Sde-Boqer does not vary much during summer, so that meteorological conditions are very similar from day to day. Then the selection of any particular day in preference of another made no little difference in terms of global environmental conditions. Selected days are 7 July 2007 for Exposed-Bare experiment and 9 August 2007 for Exposed-Grass experiment.

The offline approach used here for the SURFEX simulations requires building a set of atmospheric forcings including atmospheric pressure, temperature, specific humidity and wind speed at a prescribed vertical level, as well as incoming shortwave and longwave radiation, and rain rate. The altitude of the forcing level must be defined above the roughness surface layer, i.e., at least twice the height of roughness elements.

In the present case, no meteorological data (except radiation) was collected at the experimental site above rooftop level. The forcings are consequently defined starting from the data of the nearby meteorological station. Since they are initially available at $1.5 \mathrm{~m}$ above ground level (a.g.l.) for temperature and humidity, and at $10 \mathrm{~m}$ a.g.l. for wind, a simple method of correction by successive iterations performed with SURFEX (Lemonsu et al., 2012) is proposed to reconstruct a new forcing dataset for temperature and humidity at $10 \mathrm{~m}$ a.g.l. while the buildings are $3 \mathrm{~m}$ high.

\subsection{Results and discussion}

The two versions TEB-Veg and TEB-ISBA are run over the day selected for each experiment Exposed-Bare and Exposed-Grass. However, in order to prevent problems in the initialisation of prognostic variables, the forcing is duplicated, so that one day of spin-up is systematically laid down to the model. For the TEB-Veg simulation, microclimatic variables such as air temperature, humidity and wind speed, can be directly compared with measurements recorded within the courtyard. But, since these parameters are simulated separately by TEB and ISBA for the TEB-ISBA version, they have to be averaged according to the respective 
Table 2. TEB's and ISBA's input parameters according to the two landscaping strategies modelled with TEB-ISBA and TEB-Veg.

\begin{tabular}{|c|c|c|c|c|c|}
\hline & & \multicolumn{2}{|c|}{ Exposed-Bare } & \multicolumn{2}{|c|}{ Exposed-Grass } \\
\hline & & TEB-Veg & TEB-ISBA & TEB-Veg & TEB-ISBA \\
\hline \multicolumn{6}{|l|}{ Geometric parameters } \\
\hline Town fraction (TEB) & $(-)$ & 1.0 & 0.80 & 1.0 & 0.48 \\
\hline Nature fraction (ISBA) & $(-)$ & 0.0 & 0.20 & 0.0 & 0.52 \\
\hline Building fraction & $(-)$ & 0.35 & 0.35 & 0.35 & 0.35 \\
\hline Garden fraction & $(-)$ & 0.20 & - & 0.52 & - \\
\hline Wall-plan area ratio & $(-)$ & 0.71 & 0.88 & 0.71 & 1.46 \\
\hline Building height & (m) & 3.0 & 3.0 & 3.0 & 3.0 \\
\hline Canyon aspect ratio & $(-)$ & 0.55 & 0.78 & 0.55 & 2.70 \\
\hline \multicolumn{6}{|c|}{ Soil and vegetation properties } \\
\hline Type & $(-)$ & \multicolumn{2}{|c|}{ Bare soil (loess) } & \multicolumn{2}{|c|}{ Durban grass } \\
\hline Vegetation fraction & $(-)$ & \multicolumn{2}{|c|}{0.0} & \multicolumn{2}{|c|}{0.95} \\
\hline Leaf area index (LAI) & $(-)$ & \multicolumn{2}{|c|}{0.0} & \multicolumn{2}{|c|}{2.0} \\
\hline Height of trees & $(\mathrm{m})$ & \multicolumn{2}{|r|}{-} & \multicolumn{2}{|c|}{-} \\
\hline Roughness length & $(\mathrm{m})$ & \multicolumn{2}{|c|}{0.002} & \multicolumn{2}{|c|}{0.01} \\
\hline Albedo & $(-)$ & \multicolumn{2}{|c|}{0.30} & \multicolumn{2}{|c|}{0.20} \\
\hline Emissivity & $(-)$ & \multicolumn{2}{|c|}{0.90} & \multicolumn{2}{|c|}{0.95} \\
\hline
\end{tabular}
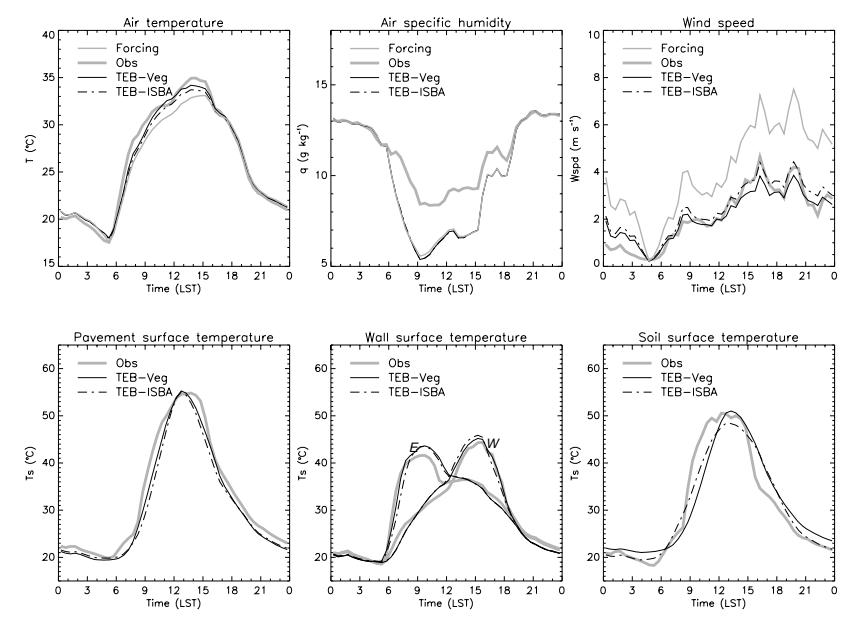

Fig. 5. Comparison of the TEB-Veg and TEB-ISBA results (black thin lines) with observations collected within the courtyards (gray thick line) for the Exposed-Bare experiment. For air temperature, specific humidity and wind speed, the gray thin line indicates the forcing data at $10 \mathrm{~m}$ a.g.l. For walls, surface temperature measurements are plotted by facet for both eastern (E) and western (W) walls.

fractions of pervious and impervious covers that compose the courtyard in order to be confronted with observations. These are the results that are presented afterwards.

\subsubsection{Exposed-Bare experiment}

For the Exposed-Bare experiment, the courtyard's landscaping is made of $70 \%$ of pavement and $30 \%$ of bare soil in the middle of the courtyard (see Fig. 1 right in ShashuaBar et al., 2009). The comparisons between TEB-Veg/TEBISBA outputs and observations are presented in Fig. 5 for air temperature, specific humidity and wind speed at $1.5 \mathrm{~m}$ a.g.l. within the canyon, as well as for surface temperatures of pavement, eastern and western walls, and soil. Biases and root-mean-square errors (rmse) are also provided in Table 3. They are calculated for the whole day, as well as for daytime and nighttime hours separately.

Both simulations give fairly similar results for the various parameters that are evaluated. The intrinsic error on the definition of the urban geometry, which is systematically done in the TEB-ISBA version by dissociating pervious and impervious covers (as explained in Sect. 5.2, Table 2), is small because the bare soil only covers $30 \%$ of the courtyard. As a result, the impact on radiation calculation is not very significant: a decrease of about $5-10 \%$ in the short- and longwave radiation absorbed by roads and walls is noted (not shown here), and their surface temperatures are little affected. The main difference relates to the temperature of bare soil. In the morning, the net radiation for bare soil is lower in TEBVeg than in TEB-ISBA because the shadow effects restrain the penetration of shortwave radiation in the canyon. Around midday, the bare soil in TEB-Veg receives more energy. Indeed, the shadow effects are reduced and an additional energy input comes from the other facets that have warmed during the morning and emit in the form of infrared radiation. As a result, the soil temperature increases later in TEBVeg than in TEB-ISBA, but becomes warmer about $2.5^{\circ} \mathrm{C}$. In the afternoon, the radiation trapping counterbalances the shadow effects in TEB-Veg. Then at night, only the trapping 
Table 3. Bias (Model-Obs) and root-mean-square error in temperature, humidity, and wind speed at 1.5 m a.g.l., and in surface temperatures of impervious and pervious covers. The scores are calculated for TEB-Veg and TEB-ISBA for both Exposed-Bare and Exposed-Grass experiments over the whole day, daytime hours (06:00-18:00 LST), and nighttime hours (18:00-06:00 LST).

\begin{tabular}{|c|c|c|c|c|c|c|c|c|c|}
\hline & & \multicolumn{4}{|c|}{ Exposed-Bare } & \multicolumn{4}{|c|}{ Exposed-Grass } \\
\hline & & \multicolumn{2}{|c|}{ TEB-Veg } & \multicolumn{2}{|c|}{ TEB-ISBA } & \multicolumn{2}{|c|}{ TEB-Veg } & \multicolumn{2}{|c|}{ TEB-ISBA } \\
\hline & & Bias & Rmse & Bias & Rmse & Bias & Rmse & Bias & Rmse \\
\hline \multicolumn{10}{|l|}{ All day } \\
\hline$T_{1.5 \mathrm{~m}}$ & $\left({ }^{\circ} \mathrm{C}\right)$ & -0.08 & 0.64 & -0.29 & 0.85 & -0.05 & 0.65 & -0.87 & 1.30 \\
\hline$q_{1.5 \mathrm{~m}}$ & $\left(\mathrm{~g} \mathrm{~kg}^{-1}\right)$ & -1.16 & 1.72 & -1.15 & 1.71 & -0.50 & 0.85 & -0.52 & 0.81 \\
\hline$U_{1.5 \mathrm{~m}}$ & $\left(\mathrm{~m} \mathrm{~s}^{-1}\right)$ & -0.12 & 0.45 & +0.21 & 0.40 & -0.16 & 0.69 & +0.56 & 0.66 \\
\hline$T_{\text {Sroad }}$ & $\left({ }^{\circ} \mathrm{C}\right)$ & -1.67 & 2.08 & -2.10 & 2.90 & & & & \\
\hline$T_{\text {Swall }_{\text {(East) }}}$ & $\left({ }^{\circ} \mathrm{C}\right)$ & -0.10 & 1.48 & -0.34 & 1.75 & +0.50 & 1.66 & -0.34 & 3.07 \\
\hline$T_{\text {Swall }_{\text {(West) }}}$ & $\left({ }^{\circ} \mathrm{C}\right)$ & -0.07 & 1.01 & -0.02 & 1.30 & +0.05 & 0.84 & -0.12 & 2.16 \\
\hline$T_{\text {Ssoil }}$ & $\left({ }^{\circ} \mathrm{C}\right)$ & +0.42 & 4.03 & +0.02 & 2.93 & & & & \\
\hline$T_{\text {Sgrass }}$ & $\left({ }^{\circ} \mathrm{C}\right)$ & & & & & -0.56 & 1.58 & -0.62 & 2.10 \\
\hline \multicolumn{10}{|l|}{ Daytime } \\
\hline$T_{1.5 \mathrm{~m}}$ & $\left({ }^{\circ} \mathrm{C}\right)$ & -0.54 & 0.82 & -0.94 & 1.14 & -0.56 & 0.75 & -1.71 & 1.85 \\
\hline$q_{1.5 \mathrm{~m}}$ & $\left(\mathrm{~g} \mathrm{~kg}^{-1}\right)$ & -2.29 & 2.44 & -2.28 & 2.44 & -0.97 & 1.21 & -0.97 & 1.15 \\
\hline$U_{1.5 \mathrm{~m}}$ & $\left(\mathrm{~m} \mathrm{~s}^{-1}\right)$ & -0.29 & 0.45 & +0.06 & 0.25 & -0.46 & 0.67 & +0.41 & 0.50 \\
\hline$T_{\text {Sroad }}$ & $\left({ }^{\circ} \mathrm{C}\right)$ & -2.04 & 2.64 & -3.17 & 3.97 & & & & \\
\hline$T_{\text {Swall }_{\text {(East) }}}$ & $\left({ }^{\circ} \mathrm{C}\right)$ & +0.47 & 1.91 & -0.07 & 2.37 & +1.08 & 2.32 & -1.67 & 4.24 \\
\hline$T_{\text {Swall }_{\text {(West) }}}$ & $\left({ }^{\circ} \mathrm{C}\right)$ & +0.34 & 1.29 & +0.38 & 1.76 & +0.38 & 1.10 & -0.97 & 2.94 \\
\hline$T_{\text {Ssoil }}$ & $\left({ }^{\circ} \mathrm{C}\right)$ & -1.12 & 5.34 & -0.45 & 4.07 & & & & \\
\hline$T_{\text {Sgrass }}$ & $\left({ }^{\circ} \mathrm{C}\right)$ & & & & & -1.43 & 2.20 & +0.23 & 2.47 \\
\hline \multicolumn{10}{|l|}{ Nighttime } \\
\hline$T_{1.5 \mathrm{~m}}$ & $\left({ }^{\circ} \mathrm{C}\right)$ & +0.37 & 0.41 & +0.37 & 0.42 & +0.47 & 0.54 & -0.02 & 0.22 \\
\hline$q_{1.5 \mathrm{~m}}$ & $\left(\mathrm{~g} \mathrm{~kg}^{-1}\right)$ & -0.03 & 0.21 & -0.02 & 0.21 & -0.04 & 0.13 & -0.08 & 0.12 \\
\hline$U_{1.5 \mathrm{~m}}$ & $\left(\mathrm{~m} \mathrm{~s}^{-1}\right)$ & +0.04 & 0.45 & +0.37 & 0.52 & +0.14 & 0.72 & +0.70 & 0.80 \\
\hline$T_{\text {Sroad }}$ & $\left({ }^{\circ} \mathrm{C}\right)$ & -1.30 & 1.38 & -1.03 & 1.15 & & & & \\
\hline$T_{\text {Swall }_{\text {(East) }}}$ & $\left({ }^{\circ} \mathrm{C}\right)$ & -0.67 & 0.91 & -0.61 & 0.82 & -0.08 & 0.47 & +0.99 & 1.11 \\
\hline$T_{\text {Swall }_{\text {(West) }}}$ & $\left({ }^{\circ} \mathrm{C}\right)$ & -0.48 & 0.65 & -0.43 & 0.60 & -0.28 & 0.48 & +0.74 & 0.94 \\
\hline$T_{\text {Ssoil }}$ & $\left({ }^{\circ} \mathrm{C}\right)$ & +1.97 & 2.14 & +0.49 & 1.03 & & & & \\
\hline$T_{\text {Sgrass }}$ & $\left({ }^{\circ} \mathrm{C}\right)$ & & & & & +0.30 & 0.49 & -1.46 & 1.71 \\
\hline
\end{tabular}

of longwave radiation within the canyon operates, which substantially reduces the soil cooling, so that the surface temperature remains $1-2{ }^{\circ} \mathrm{C}$ warmer in TEB-Veg than in TEBISBA.

The comparison of model outputs with observations displays varying performances according to the parameters. The pavement surface temperature - referred to as $T_{\text {Sroad }}$ in Table 3 - is correctly simulated, but slightly underestimated with biases of about $-2.0^{\circ} \mathrm{C}$ at daytime and $-1.3{ }^{\circ} \mathrm{C}$ at nighttime for TEB-Veg (against -3.2 and $-1.0^{\circ} \mathrm{C}$, respectively, for TEB-ISBA). In addition, the rmse do not exceed $2.6^{\circ} \mathrm{C}$ at daytime and $1.4^{\circ} \mathrm{C}$ at nighttime for TEB-Veg. The new radiation calculation that specifies the canyon orientation and explicitly dissociates the two walls (see Sect. 3) makes possible to realistically simulate the surface temperature of both eastern and western walls. Rmse of $1.3-1.9^{\circ} \mathrm{C}$ are obtained for TEB-Veg $\left(1.8-2.4{ }^{\circ} \mathrm{C}\right.$ for TEB-ISBA) at day. At night, they do not exceed $1^{\circ} \mathrm{C}$ whatever the model's version. For bare soil, TEB-Veg overestimates the surface temperature at night, but better simulates the daily maximum than TEB-ISBA.

Air temperature and wind speed at $1.5 \mathrm{ma}$ a.g.l. are well simulated by both models. TEB-Veg is, however, slightly better by simulating higher temperatures at daytime (Fig. 5). This is confirmed by the statistical scores (Table 3). Finally, the specific humidity within the courtyard is strongly underestimated by TEB-Veg and TEB-ISBA between 06:00 and 19:00 LST. Given very dry conditions and surface materials in the courtyard (only pavement and bare soil), the models simulate a specific humidity which is substantially equal to that imposed as forcing above the canopy level (and very similar to those collected at the meteorological station). This 

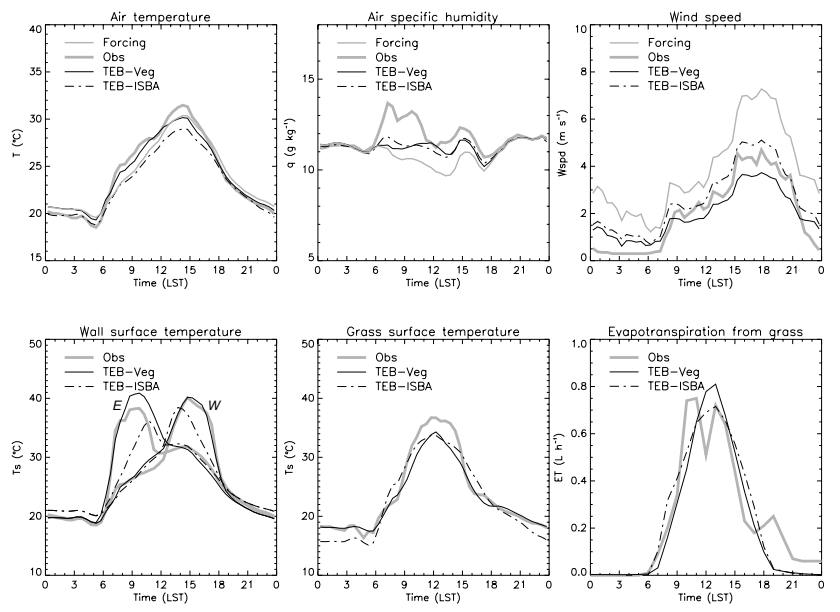

Fig. 6. Same as Fig. 5 for the Exposed-Grass experiment.

is physical evidence that, without any source of humidity, the value should be the same in and above the canyon. The specific humidity measured at the meteorological station is, however, unusually dry during daytime (less than $6 \mathrm{~g} \mathrm{~kg}^{-1}$ ). This sharp drop that is not observed inside the courtyard is possibly due to an error in measurement. A test of the model's sensitivity to forcings showed that the humidity conditions do not affect the modelling of other meteorological variables (not presented here). There was no source of humidity outside the canyon (as an irrigated park for example). Overall, for this particularly dry case, TEB-veg performs better than TEB-ISBA.

\subsubsection{Exposed-Grass experiment}

The comparisons between TEB-Veg and TEB-ISBA outputs, and observations are presented in Fig. 6 (and in Table 3 for statistical scores) for air temperature, specific humidity and wind speed at $1.5 \mathrm{~m}$ a.g.l. within the canyon, as well as for surface temperatures of pavement and grass, and evapotranspiration from grass. In this experiment, more significant differences are highlighted between the two versions of the model.

Given the more realistic transcription of the real geometry of the canyon in TEB-Veg than in TEB-ISBA, the surface temperatures are consistently better simulated. At night when the radiation trapping plays a key role by limiting the surface cooling, the wall surface temperature simulated by TEBISBA is too warm because the canyon is too narrow: for eastern wall, for instance, bias and rmse calculated for nighttime hours (Table 3 ) are +0.99 and $1.11^{\circ} \mathrm{C}$ for TEB-ISBA against -0.08 and $0.47^{\circ} \mathrm{C}$ for TEB-Veg (same trends are obtained for western wall). During daytime, the wall facets remain too long in the shade in the TEB-ISBA simulation which gives worse scores than TEB-Veg (rmse reaches $4.24^{\circ} \mathrm{C}$ for the eastern wall in TEB-ISBA instead $2.32^{\circ} \mathrm{C}$ in TEB-Veg). In contrast, since the vegetation is assimilated to an open area in
TEB-ISBA, the grass temperature is too cold at night and too warm during the day. In this case, rmse are 1.71 and $2.47^{\circ} \mathrm{C}$ for TEB-ISBA against 0.49 and $2.20^{\circ} \mathrm{C}$ for TEB-Veg.

The air temperature inside the courtyard is also better reproduced by TEB-Veg than TEB-ISBA. According to TEBVeg, the daytime air temperature is warmer inside the canyon than above, which is in agreement with what is observed. On the contrary, TEB-ISBA simulates an effect of cooling inside the canyon which is due to the shadow effects amplified by the canyon geometry. This leads to an underestimation of $-1.71^{\circ} \mathrm{C}$ for daytime hours (against $-0.56^{\circ} \mathrm{C}$ only for TEBVeg). It is also interesting to emphasize that for this experiment, the air mass in the courtyard is more humid than the atmosphere above due to the evaporation from the lawn which is irrigated. Both model's versions are able to simulate this phenomenon, even if they seem to underestimate the humidity transfer between surface and atmosphere in the first metre above the ground inside the canyon. It is noted that TEBISBA performs slightly better than TEB-Veg in the morning because the lawn receives more radiation (no shadow effect over grass in TEB-ISBA as explained in the previously section) and consequently evaporates more. Then, TEB-Veg is better at midday when the net radiation over the lawn is increased by infrared emissions coming from walls, and when the evaporation is maximum.

\subsubsection{Impact of canyon orientation}

Besides the comparisons of TEB-ISBA and TEB-Veg presented in the two previous sections, a specific analysis is performed in order to quantify the impact of the new radiation calculation that takes into account the canyon orientation and explicitly dissociates (or not) the two walls. The ExposedGrass experiment is performed with TEB-Veg, but following three methods of radiation calculation for the canyon: (1) the first method is based on the classical approach applied in TEB (according to Masson, 2000) where canyon orientations are assumed to be isotropic and where the radiation budget is computed for an averaged wall; (2) the second method makes possible to prescribe a specific orientation in the canyon, but still by dealing with an averaged wall; and (3) the last version resolves explicitly a separate radiation budget for each wall of the canyon.

The wall surface temperatures simulated with the three methods are presented in Fig. 7 and compared with observations. As already commented in the previous section, the most sophisticated method for radiation calculation - that considers a specific canyon orientation and two distinct walls - makes possible to simulate surface temperatures of eastern and western walls that are both in good agreement with observations (see the statistical scores in Table 3). When the walls are not differentiated, the quantity of energy received by the average wall is the same as the sum of the quantities of energy received by the two distinct walls. As a result, the surface temperatures are the same, on average, since at present 

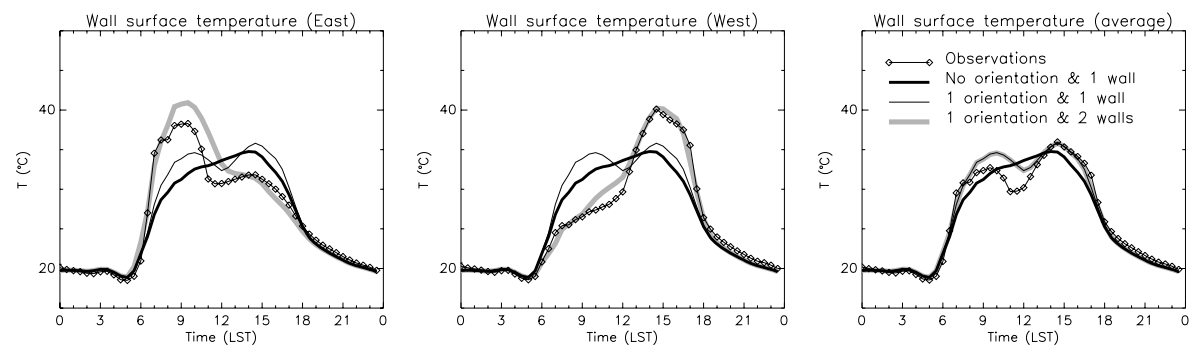

Fig. 7. Comparison of observed and modelled wall surface temperatures (for eastern and western walls separately, and in average) for the Exposed-Grass experiment. For the model, the three methods of radiation calculation are presented: (1) no specific canyon orientation and 1 wall, (2) 1 canyon orientation and 1 wall, and (3) 1 canyon orientation and 2 walls.

the two walls are identical in terms of thermal and radiative properties. Finally, the comparison indicates that the classical approach which integrates all canyon orientations simulates less realistic wall surface temperatures. For the canyon studied here (almost north-south), this version underestimates the peaks of energy received in the morning and the afternoon, while overestimating the quantity of energy received at midday which affects directly the surface temperatures.

In a second step, the impact of this new parameterisation on the other simulated variables is studied. The biases of the three versions of the model versus observations are presented in Fig. 8. It is noted that the effects are quite small. In the new version of radiation calculation - which considers the real orientation of the canyon - the specific humidity is slightly underestimated because grass surface temperature is cooler, so that the evapotranspiration from grass is a bit weaker. This grass surface temperature is nevertheless in better agreement with the measurements, but since the exchanges in moisture to the atmosphere are too weak (see the previous section) the air within the canyon remains too dry. The gain in energy for walls in the morning induces a more efficient warming of air temperature $\left(+0.2-0.4^{\circ} \mathrm{C}\right.$ between the versions), which is more consistent with observations.

\section{Conclusions}

The objective of this study is to improve the representation of urban green areas in the SURFEX land surface modelling system by including explicitly the gardens within the TEB's urban canyon. Thus, a version of the model called TEB-Veg was developed. It is first based on new radiation calculations for a canyon composed of a portion of road and garden. Orientation of the road and distinction of the thermal evolution of the two walls are also introduced in the model. This approach takes into account the shadow effects for gardens. The surface exchanges between vegetation and atmosphere are then calculated by considering the "real" short- and longwave radiation received by gardens, as well as microclimatic conditions (temperature, humidity and wind) within the canyon instead of those above the top of the canopy.
Inversely, the microclimate within the canyon is resolved by including the contributions from gardens in heat, moisture and momentum. Besides, a new parameterisation for mixing length based on Santiago and Martilli (2010) is implemented.

A major interest of our approach is that it uses the ISBA model for resolving the surface exchanges between vegetation and atmosphere. Indeed, ISBA is a robust SVAT model used for several decades for research and weather forecasting. On the other hand, there are several versions of ISBA, especially including carbon fluxes and interactive vegetation, which suggest interesting applications relative to climate and cities.

TEB-Veg was evaluated and compared with the TEBISBA initial version at the site of Sde-Boqer by using microclimatic data collected in two semi-enclosed courtyards, one composed of a concrete road and bare soil, and one of concrete and grass. It is noted that the TEB-Veg version performs better than TEB-ISBA for several reasons. First, the real geometry of courtyards is better characterised by TEBVeg than by TEB-ISBA. Indeed, by simulating the gardens outside urban spaces, TEB-ISBA systematically prescribes too narrow canyons. The results show a significant impact on the quality of simulations of radiative temperatures for walls and ground-based surfaces, especially at night when radiation trapping effects are dominant. Moreover, taking into account the microclimatic conditions in the canyon for the surface/atmosphere exchanges for gardens seems to improve the results of TEB-Veg. The wind speed is weaker than over an open area; this impacts positively on the daytime surface temperature for the first experiment with bare soil. For the experiment with lawn, the sensible heat flux over gardens is lower in TEB-Veg than in TEB-ISBA in favour of the latent heat flux, which leads to a better simulation of evapotranspiration. Modelled air temperature within the courtyard is also in better agreement with observations: TEB-Veg succeeds in simulating microclimatic conditions inside the courtyard that are warmer than above the canopy.

In conclusion, the results obtained with TEB-Veg and presented here are encouraging and demonstrate the value of an explicit coupling between impervious covers and vegetation for mixed urban environments that include a significant 

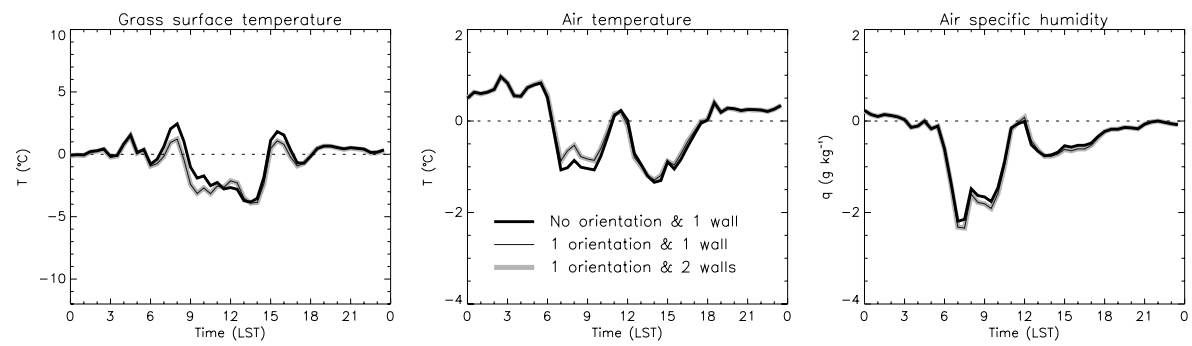

Fig. 8. Temporal evolution of biases (Model-Obs) in grass surface temperature, in air temperature and specific humidity for the ExposedGrass experiment simulated with the three methods of radiation calculation (same as Fig. 7).

portion of green areas. In view of the findings of Lee (2011), the impact of this new parameterisation on the surface/atmosphere exchanges should be studied for other meteorological situations, above all for less dry conditions that favour the role of vegetation. Finally, new developments are under way in order to improve the current version by taking into account other types of urban vegetation, more particularly street trees, green walls and green roofs. These improvements will make possible the modelling and evaluation of greening strategies for cities within the context of climate change.

\section{Appendix A}

\section{Solar reflection calculations including canyon orientation and gardens}

\section{A1 Solar radiation received by each surface}

In order to compute the solar energy stored by each surface (each one of the two walls, the road, the garden), one needs first to determine how much solar radiation is received by each surface (depending on shadowing effects). Then reflections between surfaces have to be computed. In TEB, an infinite number of reflections is considered.

The solar reflection depends on the solar position (zenithal and azimuthal angles) and canyon geometric characteristics (height, width, orientation). In the classical version of TEB (no specific canyon orientation chosen, all orientations averaged), the direct solar radiation is given by Eq. (13) and Eq. (14) of Masson (2000) for roads and walls, respectively. The direct radiation for gardens is equal to the one for roads.

If one chooses to simulate a specific canyon, defined by its orientation $\theta_{\text {can }}$, then, the direct solar radiation flux on roads, gardens and walls is:

$$
\begin{aligned}
S_{\mathrm{r}}^{\Downarrow} & =S^{\Downarrow} \max \left[0,1-\frac{\frac{h}{w} \tan (\lambda)}{\sin \left|\theta_{\text {sun }}-\theta_{\text {can }}\right|}\right] \\
S_{\mathrm{g}}^{\Downarrow} & =S_{\mathrm{r}}^{\Downarrow} \\
S_{\mathrm{w}_{\mathrm{A}}}^{\Downarrow} & =S^{\Downarrow}\left(1-S_{\mathrm{r}}^{\Downarrow}\right) \frac{w}{h} \\
S_{\mathrm{w}_{\mathrm{B}}}^{\Downarrow} & =0
\end{aligned}
$$

where $\lambda$ and $\theta_{\text {sun }}$ are the solar zenithal and azimuthal angles, $h$ is the height of buildings, $w$ the width of the canyon (including road and garden) and $S^{\Downarrow}$ is the incoming solar flux above buildings level. $S_{*}^{\Downarrow}$ is the direct solar radiation flux received at each surface ( $\mathrm{W} \mathrm{m}^{-2}$ of surface). The subscript $*$ stands for road $(\mathrm{r})$, garden $(\mathrm{g})$, wall $\mathrm{A}\left(\mathrm{w}_{\mathrm{A}}\right)$ or wall $\mathrm{B}\left(\mathrm{w}_{\mathrm{B}}\right)$. Note that this solar radiation is different for each surface. Shadows of buildings limit the solar irradiance at the surfaces of the garden and roads. Depending on canyon orientation compared to the solar azimuthal angle, one wall is sunlit (for example wall A) while the other is in shade.

Note that these equations stand for the case of direct solar radiation. In the case of diffuse solar radiation, there is no difference between walls, and the partition between walls and roads/gardens depends simply on the sky-view factor of each surface.

\section{A2 Reflections of solar radiation by the canyon surfaces}

The model takes into account an infinite number of solar reflections between facets. This is possible by summing the absorbed solar energy by each facet at each reflection (let us name it reflection number $n$ ), when the incoming solar energy coming from other facets is known.

For the first reflection, the solar energy absorbed by each facet $\left(\mathcal{A}_{\mathrm{r}}, \mathcal{A}_{\mathrm{g}}, \mathcal{A}_{\mathrm{w}_{\mathrm{A}}}\right.$ and $\mathcal{A}_{\mathrm{w}_{\mathrm{B}}}$ for road, garden, wall $\mathrm{A}$ and wall $\mathrm{B}$, respectively) is:

$$
\begin{aligned}
\mathcal{A}_{\mathrm{r}}(0) & =\left(1-\alpha_{\mathrm{r}}\right) S_{\mathrm{r}}^{\Downarrow} \\
\mathcal{A}_{\mathrm{g}}(0) & =\left(1-\alpha_{\mathrm{g}}\right) S_{\mathrm{g}}^{\Downarrow} \\
\mathcal{A}_{\mathrm{w}_{\mathrm{A}}}(0) & =\left(1-\alpha_{\mathrm{w}}\right) S_{\mathrm{w}_{\mathrm{A}}}^{\Downarrow} \\
\mathcal{A}_{\mathrm{w}_{\mathrm{B}}}(0) & =\left(1-\alpha_{\mathrm{w}}\right) S_{\mathrm{w}_{\mathrm{B}}}^{\Downarrow}
\end{aligned}
$$

where $\alpha_{*}$ is the albedo of each surface. 
The total quantity of solar energy absorbed by each surface after the $n$-th reflection from the other surfaces writes:

$$
\begin{aligned}
\mathcal{A}_{\mathrm{r}}(n+1)= & \mathcal{A}_{\mathrm{r}}(n) \\
& +\left(1-\alpha_{\mathrm{r}}\right)\left(1-\Psi_{\mathrm{r}}\right) \frac{1}{2}\left[\mathcal{R}_{\mathrm{w}_{\mathrm{A}}}(n)+\mathcal{R}_{\mathrm{w}_{\mathrm{B}}}(n)\right] \\
\mathcal{A}_{\mathrm{g}}(n+1)= & \mathcal{A}_{\mathrm{g}}(n) \\
& +\left(1-\alpha_{\mathrm{g}}\right)\left(1-\Psi_{\mathrm{r}}\right) \frac{1}{2}\left[\mathcal{R}_{\mathrm{w}_{\mathrm{A}}}(n)+\mathcal{R}_{\mathrm{w}_{\mathrm{B}}}(n)\right] \\
\mathcal{A}_{\mathrm{w}_{\mathrm{A}}}(n+1)= & \mathcal{A}_{\mathrm{w}_{\mathrm{A}}}(n)+\left(1-\alpha_{\mathrm{w}}\right)\left[\left(1-2 \Psi_{\mathrm{w}}\right) \mathcal{R}_{\mathrm{w}_{\mathrm{B}}}(n)\right. \\
& \left.+\Psi_{\mathrm{w}}\left(\delta_{\mathrm{r}} \mathcal{R}_{\mathrm{r}}(n)+\delta_{\mathrm{g}} \mathcal{R}_{\mathrm{g}}(n)\right)\right] \\
\mathcal{A}_{\mathrm{w}_{\mathrm{B}}}(n+1)= & \mathcal{A}_{\mathrm{w}_{\mathrm{B}}}(n)+\left(1-\alpha_{\mathrm{W}}\right)\left[\left(1-2 \Psi_{\mathrm{w}}\right) \mathcal{R}_{\mathrm{w}_{\mathrm{A}}}(n)\right. \\
& \left.+\Psi_{\mathrm{w}}\left(\delta_{\mathrm{r}} \mathcal{R}_{\mathrm{r}}(n)+\delta_{\mathrm{g}} \mathcal{R}_{\mathrm{g}}(n)\right)\right]
\end{aligned}
$$

where $\mathcal{R}_{*}(n)$ is the solar energy reflected by the surface during the $n$-th reflection (and then able to reach the surface one considers for absorption). Here, $\Psi_{*}$ is the sky-view factor of each surface (note that we suppose $\Psi_{\mathrm{r}}=\Psi_{\mathrm{g}}$ ), $\delta_{\mathrm{r}}$ is the fraction of road relative to the canyon surface, and $\delta_{\mathrm{g}}=1-\delta_{\mathrm{r}}$ is the fraction of garden.

The total amount of solar energy received by each surface is then:

$$
\begin{aligned}
\mathcal{A}_{\mathrm{r}}(\infty)= & \mathcal{A}_{\mathrm{r}}(0) \\
+ & \left(1-\alpha_{\mathrm{r}}\right)\left(1-\Psi_{\mathrm{r}}\right) \frac{1}{2}\left[\sum_{\infty} \mathcal{R}_{\mathrm{w}_{\mathrm{A}}}(k)+\sum_{\infty} \mathcal{R}_{\mathrm{w}_{\mathrm{B}}}(k)\right] \\
\mathcal{A}_{\mathrm{g}}(\infty)= & \mathcal{A}_{\mathrm{g}}(0) \\
+ & \left(1-\alpha_{\mathrm{g}}\right)\left(1-\Psi_{\mathrm{r}}\right) \frac{1}{2}\left[\sum_{\infty} \mathcal{R}_{\mathrm{w}_{\mathrm{A}}}(k)+\sum_{\infty} \mathcal{R}_{\mathrm{w}_{\mathrm{B}}}(k)\right] \\
\mathcal{A}_{\mathrm{w}_{\mathrm{A}}}(\infty)= & \mathcal{A}_{\mathrm{w}_{\mathrm{A}}}(0)+\left(1-\alpha_{\mathrm{w}}\right)\left[\left(1-2 \Psi_{\mathrm{w}}\right) \sum_{\infty} \mathcal{R}_{\mathrm{w}_{\mathrm{B}}}(k)\right. \\
& \left.+\Psi_{\mathrm{w}}\left(\delta_{\mathrm{r}} \sum_{\infty} \mathcal{R}_{\mathrm{r}}(k)+\delta_{\mathrm{g}} \sum_{\infty} \mathcal{R}_{\mathrm{g}}(k)\right)\right] \\
\mathcal{A}_{\mathrm{w}_{\mathrm{B}}}(\infty)= & \mathcal{A}_{\mathrm{w}_{\mathrm{B}}}(0)+\left(1-\alpha_{\mathrm{W}}\right)\left[\left(1-2 \Psi_{\mathrm{w}}\right) \sum_{\infty} \mathcal{R}_{\mathrm{w}_{\mathrm{A}}}(k)\right. \\
& \left.+\Psi_{\mathrm{w}}\left(\delta_{\mathrm{r}} \sum_{\infty} \mathcal{R}_{\mathrm{r}}(k)+\delta_{\mathrm{g}} \sum_{\infty} \mathcal{R}_{\mathrm{g}}(k)\right)\right]
\end{aligned}
$$

Then one must calculate the sum of the total energy reflected by each surface. First reflection (index 0) and any subsequent reflection (index $n+1$ ) writes:

$$
\begin{gathered}
\mathcal{R}_{\mathrm{r}}(0)=\alpha_{\mathrm{r}} S_{\mathrm{r}}^{\Downarrow} \\
\mathcal{R}_{\mathrm{g}}(0)=\alpha_{\mathrm{g}} S_{\mathrm{g}}^{\Downarrow} \\
\mathcal{R}_{\mathrm{W}_{\mathrm{A}}}(0)=\alpha_{\mathrm{w}} S_{\mathrm{w}_{\mathrm{A}}}^{\Downarrow} \\
\mathcal{R}_{\mathrm{w}_{\mathrm{B}}}(0)=\alpha_{\mathrm{w}} S_{\mathrm{w}_{\mathrm{B}}}^{\Downarrow}
\end{gathered}
$$

$$
\begin{aligned}
\mathcal{R}_{\mathrm{r}}(n+1) & =\alpha_{\mathrm{r}}\left(1-\Psi_{\mathrm{r}}\right) \frac{1}{2}\left[\mathcal{R}_{\mathrm{w}_{\mathrm{A}}}(n)+\mathcal{R}_{\mathrm{w}_{\mathrm{B}}}(n)\right] \\
\mathcal{R}_{\mathrm{g}}(n+1) & =\alpha_{\mathrm{g}}\left(1-\Psi_{\mathrm{r}}\right) \frac{1}{2}\left[\mathcal{R}_{\mathrm{w}_{\mathrm{A}}}(n)+\mathcal{R}_{\mathrm{w}_{\mathrm{B}}}(n)\right] \\
\mathcal{R}_{\mathrm{W}_{\mathrm{A}}}(n+1) & =\alpha_{\mathrm{w}}\left[\Psi_{\mathrm{w}}\left(\delta_{\mathrm{r}} \mathcal{R}_{\mathrm{r}}(n)+\delta_{\mathrm{g}} \mathcal{R}_{\mathrm{g}}(n)\right)\right. \\
& \left.+\left(1-2 \Psi_{\mathrm{w}}\right) \mathcal{R}_{\mathrm{W}_{\mathrm{B}}}(n)\right] \\
\mathcal{R}_{\mathrm{W}_{\mathrm{B}}}(n+1) & =\alpha_{\mathrm{w}}\left[\Psi_{\mathrm{w}}\left(\delta_{\mathrm{r}} \mathcal{R}_{\mathrm{r}}(n)+\delta_{\mathrm{g}} \mathcal{R}_{\mathrm{g}}(n)\right)\right. \\
& \left.+\left(1-2 \Psi_{\mathrm{w}}\right) \mathcal{R}_{\mathrm{w}_{\mathrm{A}}}(n)\right]
\end{aligned}
$$

The system involves this time cross-relations between reflections of different facets. This translates the radiative interaction between the different canyon surfaces. For sake of simplicity, let's rename $\sum_{0}^{n} \mathcal{R}_{\mathrm{r}}(k), \sum_{0}^{n} \mathcal{R}_{\mathrm{g}}(k), \sum_{0}^{n} \mathcal{R}_{\mathrm{w}_{\mathrm{A}}}(k)$, $\sum_{0}^{n} \mathcal{R}_{\mathrm{w}_{\mathrm{B}}}(k)$ as $R_{n}, G_{n}, A_{n}$ and $B_{n}$, respectively. Then, the above relations lead to:

$$
\begin{aligned}
R_{\infty} & =R_{0}+\alpha_{\mathrm{r}}\left(1-\Psi_{\mathrm{r}}\right) \frac{1}{2}\left[A_{\infty}+B_{\infty}\right] \\
G_{\infty} & =G_{0}+\alpha_{\mathrm{g}}\left(1-\Psi_{\mathrm{r}}\right) \frac{1}{2}\left[A_{\infty}+B_{\infty}\right] \\
A_{\infty} & =A_{0}+\alpha_{\mathrm{w}} \Psi_{\mathrm{w}}\left(\delta_{\mathrm{r}} R_{\infty}+\delta_{\mathrm{g}} G_{\infty}\right) \\
& +\alpha_{\mathrm{w}}\left(1-2 \Psi_{\mathrm{w}}\right) B_{\infty} \\
B_{\infty} & =B_{0}+\alpha_{\mathrm{w}} \Psi_{\mathrm{w}}\left(\delta_{\mathrm{r}} R_{\infty}+\delta_{\mathrm{g}} G_{\infty}\right) \\
& +\alpha_{\mathrm{w}}\left(1-2 \Psi_{\mathrm{w}}\right) A_{\infty}
\end{aligned}
$$

$$
\begin{aligned}
A_{\infty}= & A_{0}+\alpha_{\mathrm{w}} \Psi_{\mathrm{w}}\left(\delta_{\mathrm{r}}\left\{R_{0}+\alpha_{\mathrm{r}}\left(1-\Psi_{\mathrm{r}}\right) \frac{1}{2}\left[A_{\infty}+B_{\infty}\right]\right\}\right. \\
& \left.+\delta_{\mathrm{g}}\left\{G_{0}+\alpha_{\mathrm{g}}\left(1-\Psi_{\mathrm{r}}\right) \frac{1}{2}\left[A_{\infty}+B_{\infty}\right]\right\}\right) \\
& +\alpha_{\mathrm{w}}\left(1-2 \Psi_{\mathrm{w}}\right) B_{\infty} \\
B_{\infty}= & B_{0}+\alpha_{\mathrm{w}} \Psi_{\mathrm{w}}\left(\delta_{\mathrm{r}}\left\{R_{0}+\alpha_{\mathrm{r}}\left(1-\Psi_{\mathrm{r}}\right) \frac{1}{2}\left[A_{\infty}+B_{\infty}\right]\right\}\right. \\
& \left.+\delta_{\mathrm{g}}\left\{G_{0}+\alpha_{\mathrm{g}}\left(1-\Psi_{\mathrm{r}}\right) \frac{1}{2}\left[A_{\infty}+B_{\infty}\right]\right\}\right) \\
& +\alpha_{\mathrm{w}}\left(1-2 \Psi_{\mathrm{w}}\right) A_{\infty}
\end{aligned}
$$

This leads to (one notes $\tilde{\alpha}=\delta_{\mathrm{r}} \alpha_{\mathrm{r}}+\delta_{\mathrm{g}} \alpha_{\mathrm{g}}$ the albedo of the ground (road and garden)):

$$
\begin{aligned}
A_{\infty}-B_{\infty} & =\frac{A_{0}-B_{0}}{1+\alpha_{\mathrm{w}}\left(1-2 \Psi_{\mathrm{w}}\right)} \\
A_{\infty}+B_{\infty} & =\frac{A_{0}+B_{0}+2 \alpha_{\mathrm{w}} \Psi_{\mathrm{w}}\left(\delta_{\mathrm{r}} R_{0}+\delta_{\mathrm{g}} G_{0}\right)}{1-\tilde{\alpha} \alpha_{\mathrm{w}} \Psi_{\mathrm{w}}\left(1-\Psi_{\mathrm{r}}\right)-\alpha_{\mathrm{w}}\left(1-2 \Psi_{\mathrm{w}}\right)}
\end{aligned}
$$

And then the linear system solves as (one introduces for sake of readability the mean wall reflection $\left.W_{\infty}\right)$ :

$$
\begin{aligned}
W_{\infty} & =\frac{A_{\infty}+B_{\infty}}{2} \\
R_{\infty} & =R_{0}+\alpha_{\mathrm{r}}\left(1-\Psi_{\mathrm{r}}\right) W_{\infty} \\
G_{\infty} & =G_{0}+\alpha_{\mathrm{g}}\left(1-\Psi_{\mathrm{r}}\right) W_{\infty} \\
A_{\infty} & =W_{\infty}+\frac{1}{2} \frac{A_{0}-B_{0}}{1+\alpha_{\mathrm{w}}\left(1-2 \Psi_{\mathrm{w}}\right)} \\
B_{\infty} & =W_{\infty}-\frac{1}{2} \frac{A_{0}-B_{0}}{1+\alpha_{\mathrm{w}}\left(1-2 \Psi_{\mathrm{w}}\right)}
\end{aligned}
$$


The total solar radiation absorbed by each facet after an infinite number of reflections is finally:

$$
\begin{aligned}
\mathcal{A}_{\mathrm{r}}(\infty) & =\left(1-\alpha_{\mathrm{r}}\right)\left[S_{\mathrm{r}}^{\Downarrow}+\left(1-\Psi_{\mathrm{r}}\right) W_{\infty}\right] \\
\mathcal{A}_{\mathrm{g}}(\infty) & =\left(1-\alpha_{\mathrm{g}}\right)\left[S_{\mathrm{r}}^{\Downarrow}+\left(1-\Psi_{\mathrm{r}}\right) W_{\infty}\right] \\
\mathcal{A}_{\mathrm{w}_{\mathrm{A}}}(\infty) & =\left(1-\alpha_{\mathrm{w}}\right)\left[\frac{1}{2}\left(S_{\mathrm{w}_{\mathrm{A}}}^{\Downarrow}+S_{\mathrm{w}_{\mathrm{B}}}^{\Downarrow}\right)+\tilde{\alpha} \Psi_{\mathrm{w}} S_{\mathrm{r}}^{\Downarrow}\right. \\
& \left.+\tilde{\alpha} \Psi_{\mathrm{w}}\left(1-\Psi_{\mathrm{r}}\right) W_{\infty}+\left(1-2 \Psi_{\mathrm{w}}\right) W_{\infty}\right] \\
& +\left[\left(1-\alpha_{\mathrm{w}}\right)\left(1+\frac{\alpha_{\mathrm{w}}\left(1-2 \Psi_{\mathrm{w}}\right)}{1+\alpha_{\mathrm{w}}\left(1-2 \Psi_{\mathrm{w}}\right)}\right)\right. \\
& \left.\frac{S_{\mathrm{w}_{\mathrm{A}}}^{\Downarrow}-S_{\mathrm{w}_{\mathrm{B}}}^{\Downarrow}}{2}\right] \\
\mathcal{A}_{\mathrm{w}_{\mathrm{B}}}(\infty) & =\left(1-\alpha_{\mathrm{w}}\right)\left[\frac{1}{2}\left(S_{\mathrm{w}_{\mathrm{A}}}^{\Downarrow}+S_{\mathrm{w}_{\mathrm{B}}}^{\Downarrow}\right)+\tilde{\alpha} \Psi_{\mathrm{w}} S_{\mathrm{r}}^{\Downarrow}\right. \\
& \left.+\tilde{\alpha} \Psi_{\mathrm{w}}\left(1-\Psi_{\mathrm{r}}\right) W_{\infty}+\left(1-2 \Psi_{\mathrm{w}}\right) W_{\infty}\right] \\
& -\left[\left(1-\alpha_{\mathrm{w}}\right)\left(1+\frac{\alpha_{\mathrm{w}}\left(1-2 \Psi_{\mathrm{w}}\right)}{1+\alpha_{\mathrm{w}}\left(1-2 \Psi_{\mathrm{w}}\right)}\right)\right. \\
& \left.\frac{S_{\mathrm{w}_{\mathrm{A}}}^{\Downarrow}-S_{\mathrm{w}_{\mathrm{B}}}^{\Downarrow}}{2}\right]
\end{aligned}
$$

with

$$
W_{\infty}=\frac{\alpha_{\mathrm{w}}\left(S_{\mathrm{w}_{\mathrm{A}}}^{\Downarrow}+S_{\mathrm{w}_{\mathrm{B}}}^{\Downarrow}\right) / 2+\alpha_{\mathrm{w}} \Psi_{\mathrm{w}} \tilde{\alpha} S_{\mathrm{r}}^{\Downarrow}}{1-\tilde{\alpha} \alpha_{\mathrm{w}} \Psi_{\mathrm{w}}\left(1-\Psi_{\mathrm{r}}\right)-\alpha_{\mathrm{w}}\left(1-2 \Psi_{\mathrm{w}}\right)}
$$

\section{Appendix B}

\section{Air temperature and humidity at mid-height of building including garden contributions}

The initial version of TEB (Masson, 2000) calculates the street-level air temperature $T_{\text {can }}$ (and specific humidity $q_{\text {can }}$ ) at mid-height of buildings from the balance of all the contributions in heat (and moisture, respectively) for the air volume within the canyon:

$$
f_{\mathrm{w}} Q_{\mathrm{Hw}}+\left(1-f_{\mathrm{bld}}\right)\left\{\delta_{\mathrm{r}} Q_{\mathrm{Hr}}+\delta_{\mathrm{g}} Q_{\mathrm{Hg}}+Q_{\mathrm{Htraf}}\right\}=Q_{\mathrm{Htop}}
$$

with $f_{\mathrm{w}}, f_{\mathrm{r}}, f_{\mathrm{g}}$ and $f_{\mathrm{bld}}$ the respective fractions of walls, roads, gardens and buildings, $Q_{\mathrm{Hw}}, Q_{\mathrm{Hr}}$, and $Q_{\mathrm{Hg}}$ the sensible heat fluxes from walls, roads, and gardens, respectively, $Q_{\text {Htraf }}$ is the sensible heat flux due to traffic, and $Q_{\text {Htop }}$ the sensible heat flux between the air within the canyon and above. $Q_{\text {Htop }}$ is formally defined as in Lemonsu et al. (2004), and equal to the sum of the other fluxes to conserve energy transfer towards the atmosphere. The same expression is obtained for latent heat flux except for the wall's contribution which is not taken into account since walls cannot keep water.

Roads and gardens can be partially covered by snow, so that sensible and latent heat fluxes each count two contribu- tions coming from the fractions with and without snow. This distinction is done for roads by separating the two fluxes. For gardens, in order to keep the possibility to use any vegetation scheme (that can have various definitions of snow schemes), $Q_{\mathrm{Hg}}$ is formally calculated using a composite surface temperature (based on an average between the surface temperature of gardens without snow and the surface temperature of snow over gardens). Thus, the previous expression becomes:

$$
\begin{array}{r}
a_{\mathrm{w}} f_{\mathrm{w}} \rho C_{p}\left(T_{\mathrm{can}}-T_{\mathrm{w}}\right) \\
+\left(1-f_{\mathrm{bld}}\right)\left\{a_{\mathrm{r}} \delta_{\mathrm{r}} \delta_{r_{\mathrm{fr}}} \rho C_{p}\left(T_{\mathrm{can}}-T_{\mathrm{r}}\right)\right. \\
+\delta_{\mathrm{r}} \delta_{\mathrm{r}_{\mathrm{sn}}} Q_{\mathrm{Hr}_{\mathrm{sn}}}+a_{\mathrm{g}} \delta_{\mathrm{g}} \rho C_{p}\left(T_{\mathrm{can}}-T_{\mathrm{g}}\right) \\
\left.+Q_{\mathrm{Htraf}}\right\}=a_{\mathrm{top}} \rho C_{p}\left(T_{\mathrm{a}}-T_{\mathrm{can}}\right)
\end{array}
$$

The turbulent exchanges are calculated here by applying a system of aerodynamic conductances for heat and moisture transfers. Surface aerodynamic conductances for heat transfers over walls $\left(a_{\mathrm{w}}\right)$, roads $\left(a_{\mathrm{r}}\right)$, garden $\left(a_{\mathrm{g}}\right)$ and the aerodynamic conductances between the air within the canyon and above ( $\left.a_{\text {top }}\right)$ depend on surface roughness length, wind speed and stability condition (see Masson, 2000; Lemonsu et al., 2004; Masson et al., 2012, for details). Finally, the streetlevel air temperature can be written:

$T_{\mathrm{can}}=$

$$
\frac{a_{\mathrm{w}} f_{\mathrm{w}} T_{\mathrm{w}}+\left(1-f_{\mathrm{bld}}\right)\left\{a_{\mathrm{r}} \delta_{\mathrm{r}} \delta_{\mathrm{rfr}} T_{\mathrm{r}}+\frac{\delta_{\mathrm{r}} \delta_{\mathrm{rn}} Q_{\mathrm{Hr}}}{\rho C_{p}}+a_{\mathrm{g}} \delta_{\mathrm{g}} T_{\mathrm{g}}+\frac{Q_{\mathrm{Htraf}}}{\rho C_{p}}\right\}+a_{\mathrm{top}} T_{\mathrm{a}}}{a_{\mathrm{w}} f_{\mathrm{w}}+\left(1-f_{\mathrm{bld}}\right)\left\{a_{\mathrm{r}} \delta_{\mathrm{r}} \delta_{\mathrm{rfr}}+a_{\mathrm{g}} \delta_{\mathrm{g}}\right\}+a_{\mathrm{top}}}
$$

For humidity, the approach is more complicated because several terms must be calculated previously by ISBA in order to take into account in a consistent way the contributions of the various evaporation terms produced by the natural soils and vegetation for gardens, i.e., evapotranspiration from vegetation, evaporation from the ground (with and without freezing), and vaporisation from snow:

$Q_{\mathrm{Eg}}=Q_{\mathrm{Eg}_{\mathrm{v}}}+Q_{\mathrm{Eg}_{\mathrm{g}}}+Q_{\mathrm{Eg}_{\mathrm{g}_{i}}}+Q_{\mathrm{Eg}_{\mathrm{s}}}$

with:

$$
\begin{aligned}
Q_{\mathrm{Eg}_{\mathrm{v}}} & =a_{\mathrm{g}} f_{\mathrm{v}} \rho L_{\mathrm{v}}\left(1-\delta_{\mathrm{v}_{\mathrm{sn}}}\right) H_{\mathrm{v}}\left(q_{\mathrm{sat}}-q_{\mathrm{a}}\right) \\
Q_{\mathrm{Eg}_{\mathrm{g}}} & =a_{\mathrm{g}}\left(1-f_{\mathrm{v}}\right) \rho L_{\mathrm{v}}\left(1-\delta_{g_{\mathrm{sn}}}\right)\left(1-f_{\mathrm{g}_{\mathrm{froz}}}\right) \\
& \left(\mathrm{Hu}_{\mathrm{g}} q_{\mathrm{sat}}-q_{\mathrm{a}}\right) \\
Q_{\mathrm{Eg}_{\mathrm{g}_{i}}} & =a_{\mathrm{g}}\left(1-f_{\mathrm{v}}\right) \rho L_{\mathrm{s}}\left(1-\delta_{g_{\mathrm{sn}}}\right) f_{\mathrm{g}_{\mathrm{froz}}}\left(\mathrm{Hu}_{\mathrm{g}_{i}} q_{\mathrm{sat}}-q_{\mathrm{a}}\right) \\
Q_{\mathrm{Eg}_{\mathrm{s}}} & =a_{\mathrm{g}} \rho L_{\mathrm{s}}\left(f_{\mathrm{v}} \delta_{\mathrm{v}_{\mathrm{sn}}}+\left(1-f_{\mathrm{v}}\right) \delta_{\mathrm{g}_{\mathrm{sn}}}\right)\left(q_{\mathrm{sat}}-q_{\mathrm{a}}\right)
\end{aligned}
$$

with $f_{\mathrm{v}}$ and $f_{\mathrm{g}}$ the fractions of vegetation and ground, respectively, $\delta_{\mathrm{v}_{\mathrm{sn}}}$ and $\delta_{g_{\mathrm{sn}}}$ the fractions of vegetation and ground covered by snow, $\delta_{\mathrm{sn}}$ the cumulated grid fraction covered by snow, and $f_{\mathrm{g} \text { froz }}$ the fraction of ice in near-surface ground. $q_{\mathrm{sat}}$ is the humidity at saturation and $q_{\mathrm{a}}$ the air humidity above the top of the canopy. $H_{\mathrm{v}}$ is the Halstead coefficient (i.e., the relative humidity of vegetation canopy as defined by Noilhan and Planton, 1989), $\mathrm{Hu}_{\mathrm{g}}$ the relative humidity of bare ground, and 
$\mathrm{Hu}_{\mathrm{g}_{i}}$ the relative humidity of frozen bare ground. Finally, $L_{\mathrm{V}}$ and $L_{\mathrm{s}}$ are the vaporisation and sublimation heat coefficients.

The expression of $Q_{\mathrm{Eg}}$ for gardens is simplified in order to be expressed using a single composite aerodynamic conductance $\left(a_{\mathrm{g}}^{\prime}\right)$ and a single composite relative humidity $\left(\mathrm{Hu}_{\mathrm{g}}^{\prime}\right)$ :

$Q_{\mathrm{Eg}}=a_{\mathrm{g}}^{\prime} \rho L_{\mathrm{v}}\left(\mathrm{Hu}_{\mathrm{g}}^{\prime} q_{\mathrm{sat}}-q_{\mathrm{a}}\right)$

The composite terms can be deduced from the previous expressions of $Q_{\mathrm{Eg}_{\mathrm{v}}}, Q_{\mathrm{Eg}_{\mathrm{g}}}, Q_{\mathrm{Eg}_{\mathrm{g}_{i}}}$, and $Q_{\mathrm{Eg}_{\mathrm{s}}}$ :

$$
\begin{aligned}
a_{\mathrm{g}}^{\prime}= & \\
& a_{\mathrm{g}}\left\{f_{\mathrm{v}}\left(1-\delta_{\mathrm{v}_{\mathrm{sn}}}\right)+\left(1-f_{\mathrm{v}}\right)\left(1-\delta_{\mathrm{g}_{\mathrm{sn}}}\right)\left(1-f_{\mathrm{g}_{\mathrm{froz}}}\right)+\right. \\
& \left.\left(1-f_{\mathrm{v}}\right) \frac{L_{\mathrm{s}}}{L_{\mathrm{v}}}\left(1-\delta_{\mathrm{g}_{\mathrm{sn}}}\right) f_{\mathrm{g}_{\mathrm{froz}}}+\frac{L_{\mathrm{s}}}{L_{\mathrm{v}}}\left(f_{\mathrm{v}} \delta_{\mathrm{v}_{\mathrm{sn}}}+\left(1-f_{\mathrm{v}}\right) \delta_{\mathrm{g}_{\mathrm{sn}}}\right)\right\} \\
\mathrm{Hu}_{\mathrm{g}}^{\prime}= & \frac{a_{\mathrm{g}}}{a_{\mathrm{g}}^{\prime}}\left\{f_{\mathrm{v}}\left(1-\delta_{\mathrm{v}_{\mathrm{sn}}}\right) H_{\mathrm{v}}+\left(1-f_{\mathrm{v}}\right)\left(1-\delta_{\mathrm{g}_{\mathrm{sn}}}\right)\right. \\
& \left(1-f_{\mathrm{g}_{\mathrm{froz}}}\right) \mathrm{Hu}_{\mathrm{g}}+\left(1-f_{\mathrm{v}}\right) \frac{L_{\mathrm{s}}}{L_{\mathrm{v}}}\left(1-\delta_{g_{\mathrm{sn}}}\right) f_{\mathrm{g}_{\mathrm{froz}}} \mathrm{Hu}_{\mathrm{g}_{i}} \\
& \left.+\frac{L_{\mathrm{s}}}{L_{\mathrm{v}}}\left(f_{\mathrm{v}} \delta_{\mathrm{v}_{\mathrm{sn}}}+\left(1-f_{\mathrm{v}}\right) \delta_{\mathrm{g}_{\mathrm{sn}}}\right)\right\}
\end{aligned}
$$

Finally, the street-level air specific humidity follows the expression:

$q_{\text {can }}=$

$\frac{a_{\mathrm{r}} f_{\mathrm{r}} \delta_{\mathrm{r}_{\mathrm{wet}}} \delta_{\mathrm{r}_{\mathrm{fr}}} q_{\mathrm{r}_{\mathrm{sat}}}+\frac{f_{\mathrm{r}} \delta_{\mathrm{rsn}} Q_{E r_{\mathrm{sn}}}}{\rho L_{\mathrm{v}}}+a_{\mathrm{g}}^{\prime} f_{\mathrm{g}} \mathrm{Hu}_{\mathrm{g}}^{\prime} q_{\mathrm{g} \text { sat }}+a_{\mathrm{top}} q_{\mathrm{a}}+\frac{\left(1-f_{\mathrm{bld}}\right) Q_{\mathrm{Etraf}}}{\rho L_{\mathrm{v}}}}{a_{\mathrm{r}} f_{\mathrm{r}} \delta_{\mathrm{r}_{\mathrm{fr}}}+a_{\mathrm{g}}^{\prime} f_{\mathrm{g}} \mathrm{Hu}_{\mathrm{g}}^{\prime}+a_{\mathrm{top}}}$

where $\delta_{\mathrm{r}_{\mathrm{wet}}}$ is the fraction of roads that is wet that depends on road water reservoir (Masson, 2000).

Acknowledgements. This work has been conducted within the framework of the research projects VURCA (ANR-08VULN-013), MUSCADE (ANR-09-VILL-0003), and VegDUD (ANR-09-VILL-0007) all three funded by the French agency for research.

\section{Edited by: T. Butler}

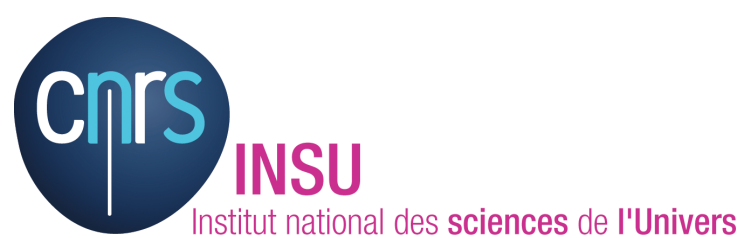

The publication of this article is financed by CNRS-INSU.

\section{References}

Boone, A., Masson, V., Meyers, T., and Noilhan, J.: The influence of the inclusion of soil freezing on simulations by a soil-vegetationatmosphere transfer scheme, J. Appl. Meteor., 9, 1544-1569, 2000.

Calvet, J.-C., Noilhan, J., Roujean, J.-L., Bessemoulin, P., Cabelguenne, M., Olioso, A., and Wigneron, J.-P.: An interactive vegetation SVAT model tested against data from six contrasting sites, Agr. Forest Meteorol., 92, 73-95, 1998.

Cuxart, J., Bougeault, P., and Redelsperger, J.-L.: A turbulence scheme allowing for mesoscale and large-eddy simulations, Q. J. Roy. Meteorol. Soc., 126, 1-30, 2000.

Dupont, S. and Mestayer, P.: Parameterization of the urban energy budget with the Submesoscale Soil Model, J. Appl. Meteorol. Climatol., 45, 1744-1765, 2006.

Essery, R., Best, M., Betts, R., Cox, P., and Taylor, C.: Explicit representation of subgrid heterogeneity in a GCM land surface scheme, J. Hydrol., 4, 530-543, 2003.

FAO/IIASA/ISRIC/ISSCAS/JRC: Harmonized World Soil Database (version 1.1), FAO, Rome, Italy and IISA, Laxenburg, Austria, 2009.

Gibelin, A.-L., Calvet, J.-C., and Viovy, N.: Modelling energy and $\mathrm{CO}_{2}$ fluxes with an interactive vegetation land surface model, Evaluation at high and middle latitudes, Agr. Forest Meteorol., 148, 1611-1628, 2008.

Grimmond, C., Blackett, M., Best, M., Barlow, J., Baik, J.-J., Belcher, S., Bohnenstengel, S., Calmet, I., Chen, F., Dandou, A., Fortuniak, K., Gouvea, M., Hamdi, R., Hendry, M., Kondo, H., Krayenhoff, S., Lee, S.-H., Loridan, T., Martilli, A., Masson, V., Miao, S., Oleson, K., Pigeon, G., Porson, A., Salamanca, F., Shashua-Bar, L., Steeneveld, G.-J., Tombrou, M., Voogt, J., and Zhang, N.: The international urban energy balance models comparison project : First results from Phase 1, J. Appl. Meteorol. Climatol., 49, 1268-1292, 2010.

Grimmond, C., Blackett, M., Best, M., Barlow, J., Baik, J.-J., Belcher, S., Bohnenstengel, S., Calmet, I., Chen, F., Dandou, A., Fortuniak, K., Gouvea, M., Hamdi, R., Hendry, M., Kondo, H., Krayenhoff, S., Lee, S.-H., Loridan, T., Martilli, A., Masson, V., Miao, S., Oleson, K., Pigeon, G., Porson, A., Salamanca, F., Shashua-Bar, L., Steeneveld, G.-J., Tombrou, M., Voogt, J., and Zhang, N.: The international urban energy balance models comparison project: Initial results from Phase 2, Int. J. Climatol., 31, 244-272, 2011.

Hamdi, R. and Masson, V.: Inclusion of a drag approach in the town energy balance (TEB) scheme : offline 1-d validation in a street canyon, J. Appl. Meteorol. Climatol., 47, 2627-2644, 2008.

Kanda, M., Kawai, T., Kanega, M., Moriwaki, R., Narita, K., and Hagishima, A.: A simple energy balance model for regular building arrays, Bound.-Lay. Meteorol., 116, 423-443, 2005.

Kondo, H., Genchi, Y., Kikegawa, Y., Ohashi, Y., Yoshikado, H., and Komiyama, H.: Development of a multi-layer urban canopy model for the analysis of energy consumption in a big city: Structure of the urban canopy model and its basic performance, Bound.-Lay. Meteorol., 116, 395-421, 2005.

Krayenhoff, E. and Voogt, J.: A microscale threedimensional urban energy balance model for studying surface temperatures, Bound.Lay. Meteorol., 123, 433-461, 2007.

Lafore, J. P., Stein, J., Asencio, N., Bougeault, P., Ducrocq, V., Duron, J., Fischer, C., Héreil, P., Mascart, P., Masson, V., Pinty, J. 
P., Redelsperger, J. L., Richard, E., and Vilà-Guerau de Arellano, J.: The Meso-NH Atmospheric Simulation System. Part I: adiabatic formulation and control simulations, Ann. Geophys., 16, 90-109, doi:10.1007/s00585-997-0090-6, 1998.

Lee, S.-H.: Further development of the Vegetated Urban Canopy Model including a grass-covered surface parametrization and photosynthesis effects, Bound.-Lay. Meteorol., 140, 315-342, 2011.

Lee, S.-H. and Park, S.-U.: A vegetated urban canopy model for meteorological and environmental modelling, Bound.-Lay. Meteorol., 126, 73-102, 2008.

Lemonsu, A., Grimmond, C., and Masson, V.: Modeling the surface energy balance of the core of an old Mediterranean city: Marseille, J. Appl. Meteorol., 43, 312-327, 2004.

Lemonsu, A., Kounkou-Arnaud, R., Desplat, J., Salagnac, J.-L., and Masson, V.: Evolution of the Parisian urban climate under a global changing climate, Climatic Change, doi:10.1007/s10584012-0521-6, online first, 2012.

Martilli, A., Clappier, A., and Rotach, M.: An urban surface exchange parameterisation for mesoscale models, Bound.-Lay. Meteorol., 104, 261-304, 2002.

Masson, V.: A Physically-Based Scheme for the Urban Energy Budget in Atmospheric Models, Bound.-Lay. Meteorol., 94, 357397, 2000.

Masson, V. and Seity, Y.: Including atmospheric layers in vegetation and urban offline surface schemes, J. Appl. Meteorol. Climatol., 48, 1377-1397, 2009.

Masson, V., Grimmond, C., and Oke, T.: Evaluation of the Town Energy Balance (TEB) scheme with direct measurements from dry districts in two cities, J. Appl. Meteorol., 41, 1011-1026, 2002.

Masson, V., Moigne, P. L., Martin, E., Faroux, S., Alias, A., Alkama, R., Belamari, S., Barbu, A., Boone, A., Bouyssel, F., Brousseau, P., Brun, E., Calvet, J.-C., Carrer, D., Decharme, B., Delire, C., Donier, S., Essaouini, K., Gibelin, A.-L., Giordani, H., Habets, F., Jidane, M., Kerdraon, G., Kourzeneva, E., Lafaysse, M., Lafont, S., Brossier, C. L., Lemonsu, A., Mahfouf, J.-F., Marguinaud, P., Mokhtari, M., Morin, S., Pigeon, G., Salgado, R., Seity, Y., Taillefer, F., Tanguy, G., Tulet, P., Vincendon, B., Vionnet, V., and Voldoire, A.: The SURFEXv7.2 land and ocean surface platform for coupled or offline simulation of Earth surface variables and fluxes, Geosci. Model Dev. Discuss., submitted, 2012.

Noilhan, J. and Planton, S.: A simple parameterisation of land surface processes for meteorological models, Mon. Weather Rev., 117, 536-549, 1989.

Offerle, B., Jonsson, P., Eliasson, I., and Grimmond, C.: Urban modification of the surface energy balance in the west African Sahel: Ouagadougou, Burkina Faso, Int. J. Climatol., 18, 39833995, 2005.
Pigeon, G., Moscicki, M., Voogt, J., and Masson, V.: Simulation of fall and winter surface energy balance over a dense urban area using the TEB scheme, Meteorol. Atmos. Phys., 102, 159-171, 2008.

Porson, A., Harman, I., Bohnenstengel, S., and Belcher, S.: How many facets are needed to represent the surface energy balance of an urban area?, Bound.-Lay. Meteorol., 132, 107-128, 2009.

Redelsperger, J.-L., Diongue, A., Diedhiou, A., Céron, J.-P., Diop, M., Gueremy, J.-F., and Lafore, J.-P.: Multiscale description of a Sahelian weather system representative of the West African monsoon, Q. J. Roy. Meteorol. Soc., 128, 1229-1257, 2002.

Roberts, S., Oke, T., Grimmond, C., and Voogt, J.: Comparison of four methods to estimate urban heat storage, J. Appl. Meteorol. Climatol., 45, 1766-1781, 2006.

Salamanca, F., Krpo, A., Martilli, A., and Clappier, A.: A new building energy model coupled with an urban canopy parameterisation for urban climate simulations part I. formulation, verification, and sensitivity analysis of the model, Theor. Appl. Climatol., 99, 331-344, 2010.

Salgado, R. and Moigne, P. L.: Coupling of the FLake model to the Surfex externalized surface model, Boreal Env. Res., 15, 231244, 2010.

Santiago, J. and Martilli, A.: A dynamic urban canopy parameterisation for mesoscale models based on computational fluid dynamics Reynolds-averaged Navier-Stokes microscale simulations, Bound.-Lay. Meteorol., 137, 417-439, 2010.

Seity, Y., Brousseau, P., Malardel, S., Hello, G., Bénard, P., Bouttier, F., Lac, C., and Masson, V.: The AROME-France convective scale operational model, Mon. Weather Rev., 139, 976-991, 2011.

Shashua-Bar, L. and Hoffman, M. E.: The green CTTC model for predicting the air temperature in small urban wooded sites, Buil. Environ., 37, 1279-1288, 2002.

Shashua-Bar, L. and Hoffman, M. E.: Quantitative evaluation of passive cooling of the UCL microclimate in hot regions in summer, Buil. Environ., 39, 1087-1099, 2004.

Shashua-Bar, L., Pearlmutter, D., and Erell, E.: The cooling efficiency of urban landscape strategies in a hot dry climate, Landscape Urban Plan., 92, 179-186, 2009.

Shashua-Bar, L., Pearlmutter, D., and Erell, E.: The influence of trees and grass on outdoor thermal comfort in a hot-arid environment, Int. J. Climatol., 31, 1498-1506, 2011.

Yamada, T.: A numerical model study of turbulent airflow in and above a forest canopy, J. Meteor. Soc. Jpn, 60, 439-454, 1982. 